\title{
LA ADMINISTRACIÓN DE JUSTICIA EN SORIA DURANTE LA II REPÚBLICA ESPAÑOLA (1931-1936)
}

\author{
Jesús GÓMEZ TIERNO \\ DOCTOR EN DERECHO POR LA UNIVERSIDAD DE LA RIOJA \\ jgomeztierno@gmail.com
}

SUMARIO: I. INTRODUCCIÓN. II. PRINCIPALES REFORMAS NORMATIVAS REPUBLICANAS SOBRE JUSTICIA. III. LA ORGANIZACIÓN DE TRIBUNALES EN SORIA Y SU ACTIVIDAD JUDICIAL EN LA II REPÚBLICA. III.1. APROXIMACIÓN. ORGANIGRAMA Y COMPETENCIAS. III.2. ÁMBITO DE ACTUACIÓN PROVINCIAL. AUDIENCIA

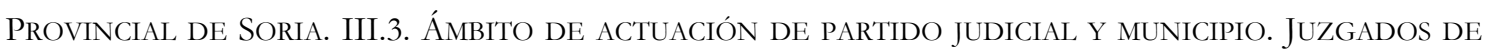
Primera Instancia e Instrucción de Ágreda, AlmazÁn, El Burgo de Osma, Medinaceli y Soria. JuZgAdos Municipales. IV. CONCLUSIONES. V. FuENTES Y BIBLIOGRAFíA.

RESUMEN: El presente trabajo analiza la organización de tribunales en Soria y su actividad judicial a lo largo de la II República española (1931-1936). Se estudian en profundidad las principales reformas normativas republicanas sobre Justicia y su implicación en la organización de tribunales sorianos y en los distintos procedimientos judiciales según su concreta jurisdicción (penal, contencioso-administrativa y civil), tanto desde el ámbito provincial (Audiencia Provincial de Soria) como también desde el de los distintos partidos judiciales y municipios (Juzgados de Primera Instancia e Instrucción y Juzgados Municipales). El trabajo constata una razonable normalidad en el funcionamiento habitual de la Administración de Justicia en Soria durante el régimen republicano, tanto a nivel organizativo y de personal como desde el punto de vista judicial y administrativo.

PALABRAS CLAVE: Segunda República Española, Soria, reformas normativas, sistema judicial, Administración de Justicia.

\section{THE ADMINISTRATION OF JUSTICE IN SORIA DURING THE SECOND SPANISH REPUBLIC (1931-1936)}

ABSTRACT: This essay analyses the organization of courts in Soria and their judicial activity during the Second Spanish Republic (1931-1936). The main republican regulatory reforms on Justice and their involvement in the organization of Sorian courts, and in the different judicial procedures according to their specific jurisdiction (criminal, contentious-administrative and civil), are studied in depth from both the provincial level (Soria Provincial Court) as well as from that of the different judicial parties and municipalities (Courts of First Instance and Instruction and Municipal Courts). The essay confirms a reasonable normality in the normal operation of 
the Administration of Justice in Soria during the republican regime, both at an organizational and personal level and from a judicial and administrative point of view.

KEY WORDS: Second Spanish Republic, Soria, regulatory reforms, judicial system, Administration of Justice.

\section{Introducción}

Ilusión y entusiasmo. Quizás fueran éstas algunas de las palabras que mejor detallarían el estado de ánimo de la sociedad española en su conjunto el 14 de abril de 1931. En esa histórica fecha se proclamó la II República en España, tras el triunfo de las candidaturas republicanas en las elecciones municipales celebradas previamente dos días antes, y con Niceto Alcalá-Zamora y Torres presidiendo el primer gobierno provisional del nuevo régimen. Siguiendo a Ramírez Jiménez, el 14 de abril de 1931 iba a pasar a la historia de España como el momento histórico más pleno de entusiasmo en el que, se decía, el nuevo régimen advenía a nuestro país sin "derramar una gota de sangre". ${ }^{1}$

En Soria se vivió la llegada de la República de la misma manera: por un lado sin ninguna violencia, y por otro, con grandes dosis de ilusión y entusiasmo. También empapados en un claro ambiente de esperanza ${ }^{2}$. La prensa soriana de la época se hizo eco desde el primer momento de lo acontecido en la capital y en la provincia tras la proclamación de la II República. ${ }^{3}$

Curiosamente, por lo que de incidencia judicial parcial e indirecta tuvo, una de las primeras medidas que se tomaron con respecto a Soria, fue el cese del gobernador civil Enrique Barranco y González Estéfani, y el nombramiento inmediato como gobernador interino del presidente de la Audiencia Provincial de Soria José María Rodríguez del Valle. Dicha máxima autoridad judicial de la provincia se encargó del mando interino del Gobierno Civil soriano desde el mismo 14 de abril de

\footnotetext{
${ }_{1}^{1}$ RAMÍREZ JIMÉNEZ, M., La legislación de la Segunda República Española (1931-1936), Madrid, Boletín Oficial del Estado, Centro de Estudios Políticos y Constitucionales, 2005, p. 12. Además del indicado, muchos estudios han abordado el análisis de los algo más de cinco años de desarrollo republicano, divididos políticamente en tres períodos: bienio reformador o republicano-socialista (1931-1933), bienio restaurador o radical-cedista (1934-1936) y período del Frente Popular (1936). Por citar solamente algunos de estos trabajos, GONZÁLEZ CALlEJA, E., COBO ROMERO, F., MARTÍNEZ RUS, A, y SÁNCHEZ PÉREZ, F., La Segunda República Española, Barcelona, Ediciones de Pasado y Presente, 2015, obra muy extensa en la que, a partir de su página 1.258, se hace referencia expresa ni más ni menos que a un total de 1.368 referencias bibliográficas sobre la II República en España; y DÍAZ-PLAJA CONTESTÍ, F., La Segunda República. Primeros pasos, Barcelona, Planeta, 1995.

2 ROMERO SALVADOR, C., "Soria, Edad Contemporánea. Siglos XIX-XX (1808-1984)”, en Historia de Soria, Tomo I, VVAA, director: José Antonio Pérez-Rioja, Soria, Centro de Estudios Sorianos, 1985, p. 498. Sin embargo, a pesar de las expectativas, la vida política siguió en manos de los mismos que la dirigían antes del 14 de abril de 1931, es decir, la República no supuso en Soria ciertamente ninguna renovación, ni de personas ni mucho menos de clases sociales. Ibid.

${ }^{3}$ El Avisador Numantino (15.4.1931), El Noticiero de Soria (16.4.1931), La Voz de Soria (17.4.1931) y Hogar y Pueblo (18.4.1931), teniendo en cuenta que todos ellos (menos Hogar y Pueblo que era semanario, con cabecera en El Burgo de Osma), tenían una periodicidad de dos días a la semana. En los mismos se reflejaban las primeras noticias recibidas en Soria sobre la proclamación de la II República, así como la gran manifestación que se llevó a cabo por las calles de la capital, y los primeros acuerdos políticos tanto locales como provinciales. También se detallaba cómo se fue extendiendo rápidamente la noticia por todos los pueblos de la provincia. En los siguientes días, se recogieron los distintos pasos dados por la sociedad soriana, así como diferentes opiniones y puntos de vista sobre el nuevo régimen.
} 
1931 hasta cuatro días después (el 18 del mismo mes y año), día en el que tomó posesión como gobernador civil Mariano Joven Hernández. ${ }^{4}$

Lo acontecido en Soria durante los algo más de cinco años de ámbito temporal de la II República (tanto en la sociedad en sí como en sus distintas instituciones políticas locales y provinciales), desde los primeros pasos antes referidos a partir del 14 de abril de 1931, hasta el alzamiento militar que supuso el inicio de una cruenta guerra civil en España el 18 de julio de 1936, teniendo en cuenta, además, que Soria quedó incorporada desde prácticamente el primer momento en el llamado "bando nacional" (por lo que se puede decir que el período republicano soriano finalizó definitivamente en los primeros días siguientes a dicha fecha de alzamiento), ha sido motivo de análisis y estudio desde distintos puntos de vista (económico, político, sociológico, poblacional, educativo.... $)^{5}$. Sin embargo, por lo que se refiere a la Justicia en Soria y su provincia durante este período republicano, no existe hasta hoy ningún estudio previo ni investigación técnico-jurídica al respecto. ${ }^{6}$

En su virtud, con el objetivo de delimitar los parámetros básicos de este estudio y llevar a cabo un riguroso análisis de los datos obtenidos tras una exhaustiva investigación sobre la

\footnotetext{
${ }^{4}$ En el Boletín Oficial Extraordinario de la Provincia de Soria de 15 de abril de 1931 se hacía referencia al nombramiento como gobernador civil interino de Soria del presidente de la Audiencia Provincial. En la Gaceta de Madrid núm. 107 de 17 de abril de 1931 (p. 222) se publicó el nombramiento de Mariano Joven Hernández como gobernador civil de Soria, siendo insertado el acuerdo también en el Boletín Oficial Extraordinario de la Provincia de Soria del 19 de abril de 1931.

5 Tanto de manera directa y monográfica sobre Soria, como con un carácter parcial y limitado. Así, GARCÍA SEGURA, M.C., Historia de la Diputación Provincial de Soria, siglo XX (años 1902-2005), Soria, Diputación Provincial de Soria, 2005, capítulo X (La Diputación de Soria durante la Segunda República y la Guerra Civil), pp. 185-306; ROMERO SALVADOR, C., "Cronología. Historia Contemporánea”, en Historia de Soria, Tomo II, VVAA, director: José Antonio Pérez-Rioja, Soria, Centro de Estudios Sorianos, 1985, pp. 80-83; CALVO VILLAR, C., "La Instrucción Pública en Soria capital durante la Segunda República Española (1931-1936)", en Celtiberia, núm. 85-86, Soria, Centro de Estudios Sorianos, 1993, pp. 159-201; SERRALLONGA URQUIDI, J., "El aparato provincial durante la Segunda República. Los gobernadores civiles, 1931-1939”, en Hispania Nova. Revista de Historia Contemporánea, Separata, núm. 7, 2007, pp. 1-52; GONZÁLEZ CALLEJA, E., Cifras cruentas. Las víctimas mortales de la violencia sociopolítica en la Segunda República Española (1931-1936), Albolote (Granada), Comares, 2015; GONZÁLEZ CALLEJA, E., "La necro-lógica de la violencia sociopolítica en la primavera de 1936”, en Mélanges de la Casa de Velázquez̧, núm. 41-1, 2011, pp. 37-60; ROLDÁN CAÑZARES, E., "La justicia de la II República Española en guerra. Una aproximación historiográfica", en Revista de Historiografía, núm. 29, 2018, pp. 37-54; RUIZ, J., El Terror Rojo, traducción de Jesús de la Torre, Barcelona, Espasa, 2012. Asimismo se puede llevar a cabo un estudio cronológico de lo acontecido en la sociedad soriana en la II República a través de lo publicado en la prensa de la época (El Avisador Numantino, El Noticiero de Soria, Hogar y Pueblo...) y en el Boletín Oficial de la Provincia de Soria. Con respecto a la prensa a nivel nacional y también con respecto a la provincia de Soria y a la suspensión en un algún período concreto de ciertos periódicos, puede verse SINOVA GARRIDO, J., La Prensa en la Segunda República Española. Historia de una libertad frustrada, Barcelona, Debate, 2006. También es interesante, en relación al período posterior a la finalización de la II República en Soria (guerra civil y posguerra), FRÍAS RUBIO, A.R., "El Tribunal de Responsabilidades Políticas de Soria. 1939-1959”, en RICUS (Geografía e Historia), Tomo XI, núm. 3, Colegio Universitario de Soria, 1990-1991, pp. 87-113; HERNÁNDEZ GARCÍA, A., 640 sorianos represaliados por Franco, 2012; y HERRERO BALSA, G, y HERNÁNDEZ GARCÍA, A, La represión en Soria durante la Guerra Civil, Soria, 1982.

${ }^{6}$ Quizás una de las parciales excepciones pueda ser GÓMEZ TIERNO, J., La Audiencia de lo Criminal de Soria, tesis doctoral, directora: Isabel Martínez Navas, Facultad de Ciencias Jurídicas y Sociales, Departamento de Derecho, Universidad de La Rioja, 2019, y el tratamiento histórico-jurídico sobre la Administración de Justicia en Soria desde la finalización del Antiguo Régimen a principios del siglo XIX y su evolución posterior, con algunos apuntes sobre determinados tribunales sorianos, ya en el siglo XX.
} 
Administración de Justicia en Soria durante la II República, se comenzará primeramente con un análisis de las principales reformas normativas, desde un punto de vista histórico-jurídico y procesal, que se aprobaron a nivel nacional durante el régimen republicano en relación con la Justicia, teniendo en cuenta al respecto tanto un punto de vista sustantivo como, sobre todo, aquél relativo a los cambios estructurales y procedimentales que se incardinaron en cada uno de los diferentes ámbitos jurisdiccionales (penal, contencioso-administrativo, civil), para continuar con el estudio en detalle de la organización de tribunales (composición y funciones) y el consiguiente desglose de la actividad judicial concreta de la Administración de Justicia en Soria y su provincia durante el histórico devenir republicano.

\section{Principales reformas normativas republicanas sobre Justicia}

El estudio que se aborda ahora sobre las principales reformas normativas que en relación con la Justicia se publicaron durante el período republicano, se ha estimado conveniente estructurarlo por concretos ámbitos de actuación en los que poder incardinar las sucesivas reformas, y no desde un punto de vista estrictamente cronológico y lineal. Por ello, se analizará la normativa republicana sobre Justicia con las reformas sucesivas que fueron entrando en vigor en relación con el ámbito constitucional, los órdenes jurisdiccionales penal y civil, el personal propio de la Judicatura, y la específica estructura general y organización judicial republicana. ${ }^{7}$

Con una sensación generalizada de debilidad estructural, antes incluso de que viera la luz la propia Constitución republicana, se aprobó la Ley de Defensa de la República de 21 de octubre de $1931^{8}$, por la que se dejaron sin efecto algunas garantías constitucionales previas, definiendo una serie de actos de agresión al régimen, consecuencias inmediatas de su realización y señalando distintas facultades del gobierno para asegurar su implementación. La Constitución republicana de 9 de diciembre de $1931^{9}$, dedicó su título VII a la Justicia (artículos 94 a 106), aunque no hacía referencia expresa alguna en su articulado a un "Poder Judicial"10. En palabras de Muñoz Machado, la Constitución de 1931 "afrontó con una decisión escalofriante en una España en que tales ideas no contaban con un mínimo consenso, cuestiones tan renovadoras y centrales como la organización descentralizada del Estado, la relación de la Iglesia con el Estado, o el régimen de la propiedad" 11. Con posterioridad, entró en vigor la Ley de Orden Público de 28 de julio de 193312, que estableció los estados de prevención, de alarma y de guerra, reduciendo considerablemente los derechos establecidos en la propia Constitución republicana. ${ }^{13}$

\footnotetext{
7 De similar modo, AQUESOLO VEGAS, J., “Apuntes sobre la Justicia en España 1931-1945. La documentación que se conserva en un archivo histórico provincial", en Los años convulsos. 1931-1945. Documentación del Archivo Histórico Provincial de Málaga, VVAA, Esther Cruces Blanco y José Aquesolo Vegas (coordinadores), Cádiz, Junta de Andalucía, Consejería de Cultura, 2006, pp. 53-65.

${ }^{8}$ Gaceta de Madrid núm. 295 de 22 de octubre de 1931, pp. 420 y 421.

${ }^{9}$ Gaceta de Madrid núm. 344 de 10 de diciembre de 1931, pp. 1578-1588.

${ }^{10}$ Quedaban abolidos los Tribunales de honor, tanto civiles como militares (art. 95).

${ }^{11}$ MUÑOZ MACHADO, S., "De la II República al siglo XXI, las transformaciones del Derecho en setenta años", en Revista Española de Derecho Constitucional, año 22, núm. 66, septiembre-diciembre 2002, p. 96.

12 Gaceta de Madrid núm. 211 de 30 de julio de 1933, pp. 682-690.

13 Se constituiría un Tribunal de Urgencia en cada una de las Audiencias Provinciales para conocer de los sumarios que bajo la Ley de Orden Público tendrían siempre la consideración de urgentes. Habrá que tener en cuenta, además, que fueron pocos los meses a partir de la aprobación de la Ley de Orden Público en los que no estuviera en vigor alguno de los estados de excepción previstos en la misma. Así, por poner varios ejemplos,
} 
Dentro del ámbito jurisdiccional penal, una de las primeras decisiones que se tomaron al proclamarse la II República fue la amnistía en relación con los delitos políticos, sociales y de imprenta, en virtud del Decreto de 14 de abril de 19314. En esa histórica fecha de la proclamación del régimen republicano, estaba en vigor el Código Penal de 8 de septiembre de 192815, procediéndose inmediatamente por Decreto de 15 de abril de 1931 a anular y dejar sin efecto el referido texto sustantivo penal ${ }^{16}$. El nuevo Código Penal republicano se comenzó a fraguar a través de la Ley de 8 de septiembre de 1932 de bases para la reforma del Código Penal de 187017, siendo aprobado el mismo definitivamente con fecha 27 de octubre de $1932^{18}$. Posteriormente, también se produjo una modificación de índole procesal en la Ley de Enjuiciamiento Criminal de 1882, al introducirse determinados cambios en el recurso de casación a través de la Ley de 28 de junio de $1933^{19}$. Además, a lo largo del período republicano, se llevaron a cabo diferentes reformas en relación con la pena de muerte. La misma, que no estaba contemplada en el Código Penal de 1932, fue reinstaurada para algunos delitos por la Ley de 11 de octubre de 193420, estableciendo al respecto la vigencia del Código Penal de $1870^{21}$, y prorrogándose posteriormente la vigencia de la pena capital para determinados delitos por la Ley de 20 de junio de $1935^{22}$. También vieron la luz sucesivas regulaciones legales sobre la tenencia y uso de armas de fuego, como la Ley de 9 de enero de $1932^{23}$ y la Ley de 4 de julio de 193324, que tuvieron su pertinente repercusión en el incremento considerable de los parámetros estadísticos de actividad judicial.

el Decreto de 9 de diciembre de 1933 declaró en todo el territorio nacional el estado de alarma (Gaceta de Madrid núm. 344 de 10 de diciembre de 1933, p. 1699); el Decreto de 12 de noviembre de 1935 acordó restablecer el régimen normal en todas las provincias menos en algunas -normalidad en Soria- (Gaceta de Madrid núm. 317 de 13 de noviembre de 1935, p. 1219); el Decreto de 17 de febrero de 1936 declaró el estado de alarma en todo el territorio nacional (Gaceta de Madrid núm. 49 de 18 de febrero de 1936, p. 1427); el Decreto de 26 de febrero de 1936 acordó el cese del estado de alarma en Soria (Gaceta de Madrid núm. 58 de 27 de febrero de 1936, p. 1635); y el Decreto de 16 de marzo de 1936 prorrogó el estado de alarma por 30 días en todo el territorio nacional -a partir de entonces la prórroga se produciría cada 30 días en lo que restara de régimen republicano- (Gaceta de Madrid núm. 77 de 17 de marzo de 1936, p. 2132).

${ }^{14}$ Gaceta de Madrid núm. 105 de 15 de abril de 1931, p. 195. También se aprobó un indulto con fecha 22 de abril de 1931 (complementando el anterior indulto contenido en el Decreto que dejó sin efecto el Código Penal de 1928 -Boletín Oficial de la Provincia de Soria de 27 de abril de 1931, p. 2-). Asimismo, una amnistía en relación con determinados delitos conforme a la Ley de 24 de abril de 1934 (Gaceta de Madrid núm. 115 de 25 de abril de 1934, pp. 548 y 549).

${ }^{15}$ Gaceta de Madrid núm. 257 de 13 de septiembre de 1928, pp. 1450-1520.

${ }^{16}$ Gaceta de Madrid núm. 106 de 16 de abril de 1931 (p. 198). Se volvió provisionalmente al Código Penal de 1870.

${ }^{17}$ Gaceta de Madrid núm. 259 de 15 de septiembre de 1932, pp. 1948-1950. En esta ley de bases no aparecía la pena de muerte. Tampoco aparecía tipificado el adulterio.

${ }^{18}$ Gaceta de Madrid núm. 310 de 5 de noviembre de 1932, pp. 818-856. Se adaptaba así la normativa sustantiva penal al marco constitucional republicano. La Orden del Ministerio de Justicia de 11 de noviembre de 1932 dispuso la clasificación de los establecimientos donde se deberían extinguir las penas.

${ }^{19}$ Gaceta de Madrid núm. 183 de 7 de julio de 1933, pp. 139-140.

${ }^{20}$ Gaceta de Madrid núm. 290 de 17 de octubre de 1934, p. 379.

${ }^{21}$ Pero sin publicidad en la ejecución de la pena capital, conforme a la ley de 9 de abril de 1900 -ley Pulido(Gaceta de Madrid núm. 100 de 10 de abril de 1900, p. 157).

${ }^{22}$ Gaceta de Madrid núm. 176 de 25 de junio de 1935, p. 2411. La pena de muerte sería restablecida plenamente por la ley de 5 de julio de 1938 (Boletín Oficial del Estado núm. 7 de 7 de julio de 1938, p. 90), y recogida también posteriormente en el Código Penal de 1944.

${ }^{23}$ Gaceta de Madrid núm. 30 de 30 de enero de 1932, p. 747.

${ }^{24}$ Gaceta de Madrid núm. 193 de 12 de julio de 1933, p. 258. 
Asimismo, dentro del ámbito jurisdiccional penal, una de las primeras reformas de calado fue el restablecimiento de la institución del Jurado, a través del Decreto de 27 de abril de 193125, siendo modificada, en algunos artículos, por el Decreto de 22 de septiembre de 193126. El restablecimiento de esta institución de la Justicia popular se hizo básicamente conforme a las prescripciones normativas y procesales de la Ley Orgánica de 20 de abril de $1888^{27}$. Posteriormente, a través de la Ley de 27 de julio de 1933, se excluyeron determinados delitos del ámbito del Tribunal del Jurado ${ }^{28}$. Esta institución del Jurado estuvo en funcionamiento hasta su suspensión en virtud del Decreto de 8 de septiembre de $1936^{29}$. Por otro lado, poco después de que viera la luz la ya referida Ley de Orden Público de 28 de julio de 1933, se aprobaría la Ley de Vagos y Maleantes de 4 de agosto de $1933^{30}$, conforme a la cual se podía declarar en estado peligroso y someter a determinadas medidas de seguridad (posterior reinserción y reeducación), entre otros, a los vagos habituales, rufianes y proxenetas, mendigos profesionales, ebrios y toxicómanos. El Decreto de 7 de diciembre de 1934 estableció tres lugares de tratamiento reeducador en relación a los vagos y maleantes. ${ }^{31}$

Una de las novedades normativas más importantes del régimen republicano, teniendo en cuenta su trascendencia social y mediática, dentro del ámbito jurisdiccional civil, fue la aprobación el 2 de marzo de 1932 de la Ley del Divorcio ${ }^{32}$, en la que se estableció que los tribunales decretarían por sentencia firme la disolución del matrimonio cuando lo pidieran ambos cónyuges de común acuerdo o cuando lo solicitara alguno de ellos por alguna causa recogida en la propia ley ${ }^{33}$. Sin transcurrir casi nada de tiempo, en cierto modo, como continuación de la misma, se aprobó la Ley de 28 de junio de 1932, a través de la cual se reducían las formas de matrimonio solamente a la civil ${ }^{34}$. Posteriormente, se suspenderían y paralizarían los pleitos de separación y divorcio por Decreto de 2 de marzo de $1938^{35}$, siendo derogada la Ley del Divorcio por Ley de 23 de septiembre de 1939.36

\footnotetext{
${ }^{25}$ Gaceta de Madrid núm. 118 de 28 de abril de 1931, pp. 360-362. La institución del Jurado tuvo su acomodo y ratificación en la Constitución republicana de 9 de diciembre de 1931 (art. 103).

${ }^{26}$ Gaceta de Madrid núm. 267 de 24 de septiembre de 1931, pp. 1970-1977. Hubo una segunda modificación a través del Decreto también de 22 de septiembre de 1931, sobre todo en cuanto a corregir erratas del texto anterior (Gaceta de Madrid núm. 273 de 30 de septiembre de 1931, pp. 2084-2091).

${ }^{27}$ Ley del Tribunal del Jurado de 1888. Gaceta de Madrid núm. 115 de 24 de abril de 1888 (en la Gaceta de Madrid núm. 116 de 25 de abril de 1888 se rectificaba la anterior al corregir varios errores).

${ }^{28}$ Gaceta de Madrid núm. 218 de 6 de agosto de 1933, p. 890.

${ }^{29}$ Se suspendió en la llamada “zona nacional”. Boletín Oficial de la Junta de Defensa Nacional de España núm. 20, Burgos 12 de septiembre de 1936 (Decreto núm. 102).

30 Gaceta de Madrid núm. 217 de 5 de agosto de 1933, pp. 874-877.

31 Gaceta de Madrid núm. 347 de 13 de diciembre de 1934, pp. 2115 y 2116. Dependiendo de las distintas circunstancias, se establecieron tres zonas en el territorio nacional (norte, centro y sur), con un lugar específico para cada una de ellas: Prisión Central de Burgos, Casa de Trabajo de Alcalá de Henares (Madrid) y antigua Prisión Central del Puerto de Santa María (Cádiz). La Ley de Vagos y Maleantes de 1933 fue modificada por la Ley de 15 de julio de 1954 -inclusión de los homosexuales- (Boletín Oficial del Estado núm. 198 de 17 de julio de 1954, p. 4862), y fue derogada por la Ley 16/1970 sobre peligrosidad y rehabilitación social de 4 de agosto de 1970 (Boletín Oficial del Estado núm. 187 de 6 de agosto de 1970, pp. 12551-12557).

32 Gaceta de Madrid núm. 71 de 11 de marzo de 1932, pp. 1762-1767.

33 En el primer caso (mutuo disenso), la competencia para conocer el asunto y dictar la correspondiente sentencia, correspondería al Juzgado de Primera Instancia e Instrucción y, en el segundo (separación y divorcio por causa justa), a la Audiencia Provincial.

${ }^{34}$ Gaceta de Madrid núm. 185 de 3 de julio de 1932, p. 60.

35 Boletín Oficial del Estado núm. 500 de 5 de marzo de 1938, p. 6100.

${ }^{36}$ Boletín Oficial del Estado núm. 278 de 5 de octubre de 1939, pp. 5574 y 5575.
} 
Por lo que se refiere al personal judicial, el Decreto-Ley de 15 de agosto de $1927^{37}$, había refundido las categorías profesionales de las autoridades judiciales en dos (jueces y magistrados). Sin embargo, sería el Decreto de 2 de junio de 193338, el que refundiría nuevamente las mismas, por lo que a partir de entonces, con excepción de los magistrados del Tribunal Supremo, presidentes de Sala de dicho Tribunal y presidentes de las Audiencias Territoriales de Madrid y Barcelona, únicamente quedaron dos grupos en la carrera judicial: magistrados de Audiencia y jueces de Primera Instancia e Instrucción ${ }^{39}$. Por su parte, en relación a la Judicatura durante la II República, la Ley de 8 de septiembre de $1932^{40}$, dispuso que podrían ser jubilados, cualquiera que fuera su edad, a su instancia o por resolución del gobierno, todos los jueces de Instrucción, magistrados y funcionarios del Ministerio Fiscal ${ }^{41}$. Por otro lado, aunque el acceso al escalón judicial inferior (jueces municipales), al inicio de la II República estaba regulado por la Ley Municipal de 5 de agosto de 190742, el Decreto de 8 de mayo de 1931 introdujo la posibilidad de designación de los jueces municipales para poblaciones no cabezas de partido judicial, con menos de 12.000 habitantes, por libre elección de los vecinos mayores de veinticinco años que figuraran en las listas electorales vigentes en la fecha de la elección ${ }^{43}$. Sin embargo, la Ley de 27 de junio de $1934^{44}$ derogó dicha normativa sobre la designación de los jueces municipales por el pueblo, volviéndose a la situación anterior regulada por la Ley Municipal de 1907 (nombramiento de jueces municipales por las Audiencias Territoriales en pleno, con asistencia de los decanos de los colegios de abogados y notarios).

A nivel general, en el ámbito organizativo y estructural de la Justicia durante la II República, fueron muy importantes el Decreto de 11 de mayo de 1931 que suprimió el Consejo Supremo de

\footnotetext{
37 Gaceta de Madrid núm. 229 de 17 de agosto de 1927, pp. 968-970.

38 Gaceta de Madrid núm. 155 de 4 de junio de 1933, pp. 1683-1688.

$39 \mathrm{Al}$ respecto, MARZAL RODRÍGUEZ, P., "Intervención política y judicatura española durante la II República", en Glossae, European Journal of Legal History, núm. 12, 2015, p. 552.

40 Gaceta de Madrid núm. 258 de 14 de septiembre de 1932, pp. 1914 y 1915.

41 Vázquez Osuna estima que con esta “depuración” de la Judicatura y del Ministerio Fiscal, manifiestamente contrarios a la República, serían jubilados entre 114 y 125 jueces, el 12\% de la carrera. La jubilación afectó a los jueces con edades comprendidas entre los 50 y los 69 años. VÁZQUEZ OSUNA, F., "La recuperación de la memoria histórica, la judicatura republicana", en XIX Congreso Estatal de Jueces para la Democracia, Barcelona, 1315 de mayo de 2004, ponencia, p. 8 (www.juecesdemocracia.es). Visita: 12.3.2020. Ya con anterioridad, al inicio de la II República, el Decreto de 15 de abril de 1931 (Gaceta de Madrid núm. 106 de 16 de abril de 1931, p. 199) dispuso que, mientras no se fijaran por ley votada en las Cortes requisitos de aptitud para los cargos de gobernadores civiles, directores generales, subsecretarios y los demás de categoría igual o superior en el orden civil o judicial, serían todos ellos de libre nombramiento del gobierno, bajo la responsabilidad del mismo. En relación a ese control gubernamental sobre la Justicia, puede verse GARCÍA LEÓN, S., "El control judicial durante la II República Española. La actuación de la Audiencia Territorial de Madrid como mecanismo de inspección de los tribunales", en Control y responsabilidad de los jueces (siglos XVI-XXI), VVAA, José SánchezArcilla Bernal (investigador principal), Madrid, Dykinson, 2017, pp. 427-470; y PAYÁ POVEDA, J., "El control gubernamental de la Justicia en el segundo bienio republicano. La inamovilidad de los jueces. La Ley Casanueva de 1935 y el traslado forzoso de magistrados y fiscales por el gobierno", en Represión y Orden Público durante la II República, la Guerra Civily el Franquismo. Una visión comparada, VVAA, José Antonio Pérez Juan y Sara Moreno Tejada (coordinadores), Cizur Menor (Navarra), Thomson Reuters. Aranzadi, 2019, pp. 163-185.

42 Gaceta de Madrid núm. 219 de 7 de agosto de 1907, pp. 533-535. Por Decreto-Ley de 30 de octubre de 1923 (Gaceta de Madrid núm. 304 de 31 de octubre de 1923, pp. 435y 436) se habían suprimido los Tribunales Municipales, quedando solamente en el ámbito municipal los Juzgados Municipales.

43 Gaceta de Madrid núm. 129 de 9 de mayo de 1931, pp. 616 y 617. Para el resto seguían en vigor las prescripciones de la Ley Municipal de 1907.

${ }^{44}$ Gaceta de Madrid núm. 182 de 1 de julio de 1934, pp. 9 y 10.
} 
Guerra y Marina, y estableció la Sala de lo Militar en el Tribunal Supremo (Sala VI) ${ }^{45}$, la Ley de 15 de septiembre de 1932 (Estatuto de Cataluña), con la creación de su Tribunal de Casación ${ }^{46}$, y la Ley de 24 de junio de 1933 estableciendo el Tribunal de Garantías Constitucionales ${ }^{47}$, entre cuyas competencias estarían el recurso de inconstitucionalidad o los conflictos entre el Estado y una región autónoma, o entre regiones autónomas entre sí. ${ }^{48}$

\section{La organización de tribunales en Soria y su actividad judicial en la II República}

\section{1. Aproximación. Organigrama y competencias}

La provincia de Soria al inicio de la II República contaba con una población total de 156.207 personas, siendo Soria capital la localidad más poblada (10.098 habitantes) ${ }^{49}$. Esta población se encontraba repartida en los cinco partidos judiciales en los que estaba dividida la provincia de Soria (Ágreda, Almazán, El Burgo de Osma, Medinaceli y Soria), demarcación judicial que, con pequeñas variaciones, prácticamente continuó en los mismos parámetros que se establecieron casi un siglo antes en $1834^{50}$. Además, en la provincia existían un total de 348 pueblos. ${ }^{51}$

45 Gaceta de Madrid núm. 132 de 12 de mayo de 1931, pp. 670 y 671.
46 Gaceta de Madrid núm. 265 de 21 de septiembre de 1932, pp. 2090-2094.
47 Gaceta de Madrid núm. 181 de 30 de junio de 1933, pp. 2331-2341.
48 A lo largo de la II República, otras disposiciones que tuvieron enorme transcendencia en el devenir del
régimen (aun cuando no directamente del todo relacionadas con la Administración de Justicia, ya que
pertenecían a los ámbitos, militar, religioso y agrario), serían las siguientes: Decreto de 22 de abril de 1931
(Gaceta de Madrid núm. 113 de 23 de abril de 1931, pp. 280 y 281), que supuso el comienzo de la reforma en
el ejército; el Decreto de 23 de enero de 1932 (Gaceta de Madrid núm. 24 de 24 de enero de 1932 , pp. 610 y
611), con la disolución de la Compañía de Jesús; Ley de 2 de junio de 1933 (Gaceta de Madrid núm. 154 de 3
de junio de 1933, pp. $1651-1653$ ), de confesiones religiosas (que limitaba la actividad de personas e instituciones
religiosas); Ley de 15 de septiembre de 1932 (Gaceta de Madrid núm. 265 de 21 de septiembre de 1932 , pp.
2095-2102) de Reforma Agraria, y su modificación por la Ley de 1 de agosto de 1935 (Gaceta núm. 222 de 10 de agosto de 1935, pp. 1288-1291).

49 Datos de 1930. Anuario Estadístico de España, año XIX, 1934, Madrid, Presidencia del Consejo de Ministros, Dirección General del Instituto Geográfico, Catastral y de Estadística, 1935, p. 15.

${ }^{50}$ Conforme al Real Decreto de 21 de abril de 1834 (Decretos de la Reina Isabel II, tomo XIX, pp. 207-209). El partido judicial más poblado en 1930 era el de Soria (con 49.251 habitantes), lo que suponía un 32\% del total provincial, siendo el partido judicial de Medinaceli (con 17.521 habitantes) el de menor población (11 \% del total provincial). Las dos localidades más pobladas de cada partido judicial en 1930 eran: Ágreda (Ágreda, 3.273, y Ólvega, 1.780), Almazán (Almazán, 3.364 y Berlanga, 2.090), El Burgo de Osma (El Burgo de Osma, 3.484, y San Esteban de Gormaz, 2.215), Medinaceli (Arcos de Jalón, 2.335, y Santa María de Huerta, 1.326 -Medinaceli tenía 810-), y Soria (Soria, 10.098, y Deza, 1.640). ROMERO SALVADOR, C., Soria 1860-1936, Aspectos demográficos, socioeconómicos, culturales y políticos, Tomo II, Soria, Publicaciones de la Diputación Provincial de Soria, Colección Temas Sorianos, 1981, pp. 9-32. La demarcación provincial de Soria (en 1833) y la división de su territorio en cinco partidos judiciales (en 1834), así como la evolución de la Administración de Justicia en Soria a lo largo de las décadas siguientes del siglo XIX, puede verse en GÓMEZ TIERNO, J., La Audiencia de lo Criminal de Soria..., op. cit., pp. 173-190.

${ }^{51}$ El partido judicial con más pueblos era el de Soria con 116, (el 33\% del total provincial), y el que menos pueblos tenía era el de Medinaceli, con 36 (10\% del total provincial). Desde su misma creación en 1834, el partido judicial de Medinaceli fue el más perjudicado con la nueva demarcación, tanto en número de habitantes como en número de pueblos. Siguiendo a Miguel Moreno, la cifra de municipios inicial en 1833 de 345 siguió a lo largo de los años, salvo una confusa alteración habida entre 1920 y 1950, ya que entre esas dos fechas, la Reseña estadística de la provincia de Soria (Instituto Nacional de Estadística, Presidencia del Gobierno, 1958), aporta ciertas variantes: en 1930 la cifra de municipios era de 348, en 1940, de 347, y en 1950 regresó a la cifra de principios de siglo, 345 (con más de 500 núcleos de población). De entonces hasta hoy, y especialmente a partir 


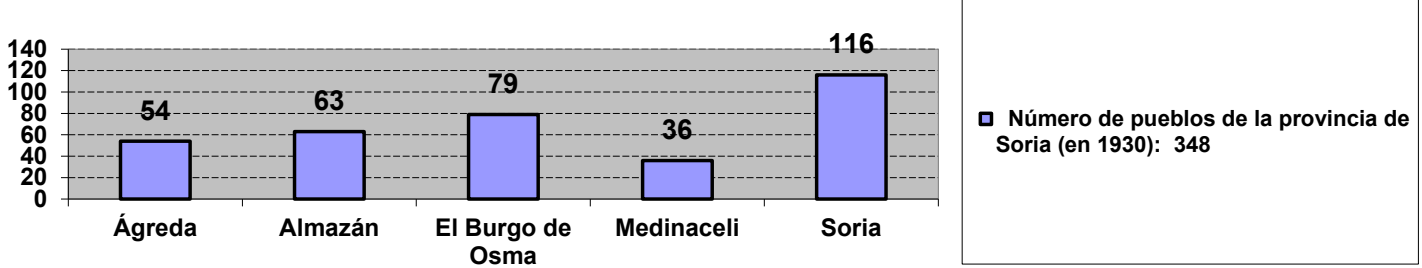

Gráfico 1. Los cinco partidos judiciales de Soria según el número de sus pueblos en 1930 (cada población contaba con Ayuntamiento y Juzgado Municipal). Fuente: Anuario Estadístico de España, año XIX, 1934, Madrid, Presidencia del Consejo de Ministros, Dirección General del Instituto Geográfico, Catastral y de Estadística, 1935, p. 15 y ss.; y ROMERO SALVADOR, C., Soria 1860-1936, Aspectos demográficos, socioeconómicos, culturales y políticos, Tomo II, Soria, Publicaciones de la Diputación Provincial de Soria, Colección Temas Sorianos, 1981, pp. 9-32. Elaboración propia.

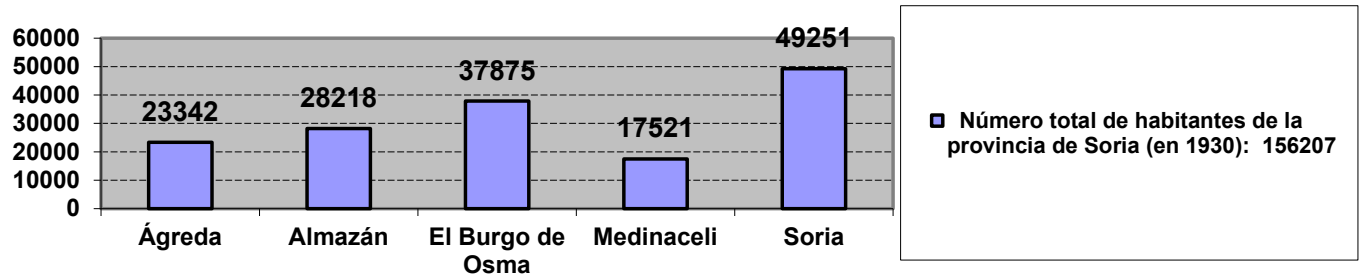

Gráfico 2. Los cinco partidos judiciales de Soria según su número de habitantes en 1930. Fuente: Anuario Estadístico de España, año XIX, 1934, Madrid, Presidencia del Consejo de Ministros, Dirección General del Instituto Geográfico, Catastral y de Estadística, 1935, p. 15 y ss.; y ROMERO SALVADOR, C., Soria 18601936, Aspectos demográficos, socioeconómicos, culturales y políticos, Tomo II, Soria, Publicaciones de la Diputación Provincial de Soria, Colección Temas Sorianos, 1981, pp. 9-32. Elaboración propia.

En cuanto al organigrama de tribunales durante la II República, Soria contaba con una Audiencia Provincial con sede en su capital y jurisdicción sobre toda su provincia, 5 Juzgados de Primera Instancia e Instrucción en la cabecera de cada uno de los otros tantos partidos judiciales existentes, y 348 Juzgados Municipales ubicados cada uno de ellos en aquel pueblo que contara con ayuntamiento propio.

La Audiencia Provincial de Soria tenía sobre todo competencias en materia penal. Conocía como Tribunal de Derecho, en única instancia y órgano judicial colegiado (Sala compuesta por tres magistrados), de los sumarios por delitos cometidos en la provincia, y que inicialmente eran instruidos por los Juzgados de Instrucción. A partir de la Ley de Orden Público de 1933, también se constituiría dentro de su ámbito de competencias el Tribunal de Urgencia (con la misma Sala) y, a raíz del restablecimiento de la institución del Jurado en 1931, siempre bajo los parámetros de la propia Audiencia Provincial, se formaría el Tribunal del Jurado, constituido por los tres magistrados de La Sala y 8 jurados, para conocer de los asuntos de su competencia ${ }^{52}$. También, dentro del ámbito de la propia Audiencia Provincial, y con competencias en materia contencioso-administrativa,

de 1962, la técnica de nuevas fusiones de municipios hizo que disminuyeran paulatinamente en número hasta dejarlo reducido en 1973 a 190 entidades municipales. MORENO MORENO, M., Biografía curiosa de Soria, Soria, 1975, p. 55. Hoy, en 2020, hay 183 municipios y 513 núcleos de población en la provincia de Soria (Instituto Nacional de Estadística -www.ine.es-. Visita: 13 de marzo de 2020).

52 Asimismo tendría determinadas competencias penales en virtud de la Ley de Vagos y Maleantes de 1933. 
desempeñaría sus funciones jurisdiccionales el Tribunal Provincial de lo Contencioso-Administrativo de Soria, formado por cinco miembros (los tres magistrados de la propia Audiencia Provincial y otros dos miembros no judiciales), y que conocía de los recursos contencioso-administrativos contra resoluciones de las diferentes administraciones públicas de la provincia. Por último, a partir de la Ley del Divorcio de 1932, también tuvo la Audiencia Provincial de Soria competencias en materia civil, ya que conocía de las demandas de divorcio por las causas recogidas en la propia ley.

Los cinco Juzgados de Primera Instancia e Instrucción de la provincia (Ágreda, Almazán, El Burgo de Osma, Medinaceli y Soria), tenían competencia en materia penal para la instrucción de los sumarios de los que luego conocía y fallaba la Audiencia Provincial. También tenían competencias en grado de apelación para conocer de los recursos contra las resoluciones dictadas en juicios de faltas por los Juzgados Municipales de su respectivo partido judicial. En materia civil conocían de la inmensa mayoría de asuntos (menos los juicios verbales de escasa cuantía atribuidos a los Juzgados Municipales), y contra cuyas sentencias en primera instancia cabía directamente recurso de apelación ante la Audiencia Territorial de Burgos. También conocían de las apelaciones contra las resoluciones dictadas por los Juzgados Municipales en los juicios verbales.

Por último, los 348 Juzgados Municipales existentes en los otros tantos municipios con ayuntamiento en la provincia de Soria, conocían en materia penal de los juicios de faltas de su término municipal, y en materia civil, de los actos de conciliación y de los juicios verbales de escasa cuantía. El juez Municipal (juez lego) también era el encargado del Registro Civil. ${ }^{53}$

\section{2. Ámbito de actuación provincial. Audiencia Provincial de Soria}

\section{III.2.1. Personal}

A lo largo de la II República, fueron un total de 35 los profesionales que ejercieron sus funciones en la Audiencia Provincial de Soria. En concreto, 6 presidentes, 8 magistrados, 3 magistrados suplentes, 2 secretarios, 6 fiscales, 3 tenientes fiscales, 2 oficiales, 3 alguaciles y 2

\footnotetext{
${ }^{53}$ En relación con la evolución de los órganos judiciales puede verse MONTÓN REDONDO, A., Jurgadosy tribunales españoles. Origenes y atribuciones, Madrid, Tecnos, 1986; CRESPO MONTES, L.F., y FERNÁNDEZ FERNÁNDEZ, M.E., "Apuntes para un estudio de la demarcación judicial española", en Boletín del Ministerio de Justicia, núm. 1624, 1992, pp. 119-165. También, en cuanto a la evolución del organigrama judicial en general y con respecto a la provincia de Soria en particular, GÓMEZ TIERNO, J., La Audiencia de lo Criminal de Soria..., op. cit., pp. 97-111. Tanto la Audiencia Provincial de Soria como el Juzgado de Primera Instancia e Instrucción de la capital, se encontraban ubicados en el edificio llamado Palacio de la Audiencia sito en la plaza Mayor de Soria. Ibid. En relación con la jurisdicción laboral, hay que tener en cuenta que con la llegada de la II República, los Comités Paritarios hasta entonces existentes (que coexistían con los Tribunales Industriales), se transformarían a finales de 1931 en los Jurados mixtos, y los mismos continuarían en funcionamiento hasta el final del régimen republicano (Ley de 27 de noviembre de 1931 de Jurados mixtos del trabajo industrial y rural, y de Jurados mixtos de la propiedad rústica -Gaceta de Madrid núm. 332 de 28 de noviembre de 1931, pp. 1251-1262-, modificada por la Ley de 16 de julio de 1935 -Gaceta de Madrid núm. 198 de 17 de julio de 1935, pp. 614-616-). Estos Jurados mixtos precisaban de su incardinación y auxilio por parte del Juzgado de Primera Instancia e Instrucción correspondiente. Al respecto, GENERELO LANASPA, J.J., "La primera jurisdicción laboral: los Tribunales Industriales y su documentación (1908-1938)", en La Administración de Justicia en la Historia de España, Actas de las III Jornadas de Castilla-La Mancha sobre investigación en arcbivos, VVAA, Guadalajara, Junta de Castilla-La Mancha, 1999, pp. 1075-1120.
} 
porteros ${ }^{54}$. En las actas de la Junta de Gobierno de la institución judicial provincial, se recogían periódicamente la toma de posesión y el cese de la inmensa mayoría de ellos ${ }^{55}$. Tras el exhaustivo estudio de las referidas actas y el de los libros y legajos gubernativos que se conservan, no consta expediente sancionador alguno. Tampoco informes negativos en relación a ninguno de los miembros del tribunal, ni sobre otro personal del órgano judicial. Las jubilaciones lo fueron por edad y los correspondientes traslados constan siempre como ordinarios. ${ }^{56}$

Por otro lado, durante la II República, en el encabezamiento de las sentencias dictadas por la Audiencia Provincial de Soria (como Tribunal de Derecho, Tribunal de Urgencia, Tribunal del Jurado y Tribunal Provincial de lo Contencioso-Administrativo), constaban como intervinientes un total de 18 abogados y 5 procuradores de los tribunales. ${ }^{57}$

54 Conforme al Decreto de 5 de julio de 1933 (Gaceta de Madrid núm. 188 de 7 de julio de 1933, pp. 141 y 142), todos los funcionarios judiciales y fiscales, y los auxiliares de la Administración de Justicia, tendrían un documento oficial de identidad para acreditar su personalidad y carácter como tales.

55 Archivo Histórico Provincial de Soria, Audiencia Provincial de Soria, signatura 7984, libro 126. También consta en dichas actas (folio 69, acta de 16 de septiembre de 1931), el nuevo juramento conforme al Decreto de 8 de mayo de 1931 (Orden de 12 de septiembre de 1931) de algunos de ellos, así como el método para proveer una plaza de magistrado suplente (folio 78, acta de 25 de febrero de 1933), "al no poderse efectuar por el rigorismo de las disposiciones vigentes, porque los varios letrados que reúnen condiciones legales, adolecen de haber desempeñado cargos gubernativos durante la Dictadura", señalando como idóneos "por su condiciones de rectitud, prestigio y probidad" a Joaquín Orense Talavera (profesor de la Escuela Normal de Maestros), Blas Taracena Aguirre (director del Museo Numantino) y Bienvenido Calvo Hernández (teniente de alcalde del ayuntamiento de Soria), -sería finalmente nombrado Blas Taracena Aguirre como magistrado suplente, folio 80, acta de 11 de marzo de 1933-.

56 Sin que para nada afecte a esta afirmación el hecho de que durante la II República (en algo más de 5 años), hubiera 6 presidentes de la Audiencia Provincial de Soria (relevos motivados por cambios organizativos y no por "depuraciones" políticas, como lo demuestra la circunstancia de que algunos de ellos fueran magistrados del propio tribunal soriano tras su período como presidentes, y otros a la inversa). Archivo Histórico Provincial de Soria, Audiencia Provincial de Soria, signatura 11.716, expedientes gubernativos. También así se hacía constar en la prensa local en alguna ocasión (despedida cariñosa a los compañeros y hacia la sociedad soriana del presidente de la Audiencia José Boza Moreno en el Avisador Numantino de 12 de noviembre de 1932). Con fecha 9 de mayo de 1932 se solicitó por parte del presidente de la Audiencia Territorial de Burgos al presidente de la Audiencia Provincial de Soria, informes reservados sobre magistrados, secretarios y jueces de los cinco partidos judiciales de la provincia, "en los que constara la capacidad, inteligencia e idoneidad para el desempeño de sus cargos, así como el que de sus respectivas vidas públicas y privadas gocen cada uno de ellos”. El oficio (dentro de un sobre reservado y personal) de contestación del presidente de la Audiencia soriana de fecha 12 de mayo de 1932, fue individual con respecto a cada uno de los interesados, y siempre positivo y favorable hacia los mismos. No obstante, ya tras el final de la II República, la Orden de 31 de julio de 1940 (Boletín Oficial del Estado núm. 221 de 8 de agosto de 1940, pp. 5495 y 5496) dispuso la formación de expediente a Ricardo Gullón Fernández, teniente fiscal de Soria el 18 de julio de 1936 (la Orden de 30 de diciembre de 1940 -Boletín Oficial del Estado núm. 78 de 4 de enero de 1941 - admitió al servicio activo al mismo, previa imposición de la sanción de traslado forzoso).

57 En paréntesis el número total de sentencias en las que consta su intervención, ordenados por orden decreciente. Abogados: Bienvenido Calvo Hernández (55), Félix Sánchez-Malo Granados (34), Luis Posada Llera (25), José Cacho Molina (19), Alfredo de Velasco (15), Pedro San Martín (14), Cesar Santiago del Riego (14), Rafael Arjona (13), Maximino de Miguel (10), Ramón Enrique Casado (9), Jesús Posada Cacho (8), Anastasio Vitoria (8), Cipriano Ruiz Pedroviejo (6), Salvador Ballesteros Usano (4), Sotero Llorente (2), Ciriaco de la Rica Diego-Madrazo (1), Abdón Sainz (1) y José de la Prada (1). Procuradores de los tribunales: Ecequiel Heras de Francisco (137), Priscilo Plaza Martínez (102), Rafael Sainz de Robles (63), José María Fresneda (58) y Joaquín Iglesias (30). Archivo Histórico Provincial de Soria, Signaturas 7965, 7966 y 7977. Audiencia Provincial de Soria. Libros de Sentencias. Libros núms. 57 a 62 y libro 96. En cuanto a los procuradores de los tribunales (que no actuaban ante el Tribunal de Urgencia), importante a nivel estatal fue el Decreto de 6 de mayo de 1933 (Boletín 
Cuadro 1. Personal de la Audiencia Provincial de Soria (1931-1936) (entre paréntesis su concreto período de actividad)

\begin{tabular}{|c|c|}
\hline Presidentes & $\begin{array}{l}\text { José María Rodríguez del Valle Ruiz (1926-1931), José Boza Moreno (1931-1932), } \\
\text { Manuel de Vicente Tutor y Guelbenzu (1932-1934), Julio Fournier Cuarros (1934), } \\
\text { Fructuoso Cid Abad (1934-1935) y Fermín Lozano Contra (1935-1937) }{ }^{58}\end{array}$ \\
\hline Magistrados & $\begin{array}{l}\text { Enrique Cerezo Carmona (1928-1931), José Boza Moreno (1929-1931), Luis Roselló } \\
\text { Serra (1931), Fermín Lozano Contra (1931), Ignacio Infante Pérez (1931-1932), José } \\
\text { Antonio Romeu Saavedra (1932), Jesús Urrutia Castillo (1933-1939) }{ }^{59} \text { y Fructuoso } \\
\text { Cid Abad (1935-1936) }\end{array}$ \\
\hline $\begin{array}{l}\text { Magistrados } \\
\text { suplentes }\end{array}$ & $\begin{array}{l}\text { Eduardo Peña Martínez (1917-1937), Alfonso de Velasco Benito (1924-1932) y Blas } \\
\text { Taracena Aguirre (1933-1936) }\end{array}$ \\
\hline Secretarios & Luciano Hernández Martín (1929-1935) y Ruperto Lafuente Galindo (1935-1941) \\
\hline Fiscales & $\begin{array}{l}\text { Luis Sanz Sandoval (1926-1931), Manuel Roan Terreiro (1931-1933), Ruperto Martín } \\
\text { Marcos (1933-1934), Atanagildo Pardo de Andrade (1934), Ángel Ricardo Ibarra } \\
\text { García (1934-1936) y Juan Cipriano Fernández Gallego (1936-1951) }\end{array}$ \\
\hline Tenientes fiscales & $\begin{array}{l}\text { Mariano Granados Aguirre (1930-1931), Juan Cipriano Fernández Gallego (1931- } \\
\text { 1933) y Ricardo Gullón Fernández (1933-1936) }\end{array}$ \\
\hline Oficiales & $\begin{array}{l}\text { Félix Granados Aguirre }\left(1926-1935 \text { oficial } 2^{\circ}, 1935-1943 \text { oficial } 1^{\circ}\right) \text { y Alfredo Llorente } \\
\text { Melendo }\left(1929-1932 \text { oficial } 3^{\circ}, 1932-1939 \text { oficial } 2^{\circ}\right)^{60}\end{array}$ \\
\hline Alguaciles & $\begin{array}{l}\text { Román García Soria (1928-1932), Liborio Torrecilla Martínez (1929-1941) } \\
\text { Eutimio de la Iglesia Hedo (1932-1962) } \\
\text { (62 }\end{array}$ \\
\hline Porteros & Sebastián Vera Díaz (1894-1941) y Serafín de Marco Andrés (1932-1938) \\
\hline
\end{tabular}

Fuente: Archivo Histórico Provincial de Soria, Audiencia Provincial de Soria. Actas de la Junta de Gobierno, signatura 7984, libro 126; Archivo Histórico Provincial de Soria, Audiencia Provincial de Soria. Expedientes gubernativos y de personal, signaturas 11700 a 11704; Archivo Histórico Provincial de Soria, Signaturas 7965, 7966 y 7977. Audiencia Provincial de Soria. Libros de Sentencias. Libros núms. 57 a 62 y libro 96. Elaboración propia.

\section{III.2.2. Actividad judicial}

\section{III.2.2.1. Jurisdicción penal}

III.2.2.1.1. Tribunal de derecho y Tribunal de Urgencia

Desde el 14 de abril de 1931 hasta el 18 de julio de 1936, la Audiencia Provincial de Soria dictó un total de 386 sentencias penales ${ }^{63}$. Los años en los que más sentencias se dictaron fueron 1933 y 1934 (con 88 sentencias en cada uno). Del total de las mismas, 279 (72\%) fueron condenatorias y 107 (28\%) absolutorias. En cuanto al número total de enjuiciados, el mismo ascendió a 508 personas, de las cuales 460 fueron varones y 48 mujeres. Del total de enjuiciados, 328 fueron condenados (64\%) y 180 absueltos (36\%). El partido judicial de la provincia que más causas penales

Oficial de la Provincia de Soria núm. 60 de 19 de mayo de 1933), que permitía a las mujeres desempeñar dicho cargo en igualdad de condiciones que los varones.

${ }^{58}$ José Boza Moreno, Fructuoso Cid Abad y Fermín Lozano Contra fueron también magistrados de la propia Audiencia Provincial de Soria.

59 Jesús Urrutia Castillo fue anteriormente juez del Juzgado de Primera Instancia e Instrucción de Soria (19311933) y, con posterioridad, presidente de la Audiencia Provincial de Soria (1939-1957).

60 Tras un año en comisión en el Tribunal de Responsabilidades Políticas de Burgos (1939-1940), Alfredo Llorente Melendo fue después oficial 1º de la Audiencia soriana entre 1940 y 1945.

${ }^{61}$ Liborio Torrecilla Martínez estuvo un año en la Audiencia Provincial de Madrid (1941-1942). Posteriormente volvió a la de Soria, desempeñando sus funciones como alguacil entre 1942 y 1964.

62 Con posterioridad, entre 1962 y 1972, Eutimio de la Iglesia Hedo continuó en la Audiencia soriana como agente judicial.

${ }^{63}$ Como Tribunal de Derecho y como Tribunal de Urgencia. Las sentencias del Tribunal del Jurado se analizarán en el siguiente epígrafe. Antes de la II República, se dictaron 9 sentencias desde el 1 de enero al 13 de abril de 1931, y posteriormente, desde el 19 de julio al 31 de diciembre de 1936, se dictaron 21 sentencias. 
instruyó y que luego fueran conocidas por la Audiencia Provincial de Soria, fue el propio de la capital (Soria) con un total de 136 sumarios instruidos (35\% del total), siendo el de Medinaceli el partido judicial con menos causas instruidas, 29 (8\% del total). ${ }^{64}$

Cuadro 2. Sentencias penales dictadas por la Audiencia Provincial de Soria según el partido judicial de procedencia (instrucción). 1931-1936 ${ }^{65}$. Tribunal de Derecho y Tribunal de Urgencia.

\begin{tabular}{|c|c|c|c|c|c|c|c|c|}
\hline Partido Judicial/Año & 1931 & 1932 & 1933 & 1934 & 1935 & 1936 & Totales & $\%$ \\
\hline Agreda & 4 & 13 & 17 & 18 & 8 & 1 & 61 & 16 \\
\hline Almazán & 10 & 16 & 15 & 19 & 13 & 6 & 79 & 20 \\
\hline El Burgo de Osma & 4 & 17 & 13 & 21 & 22 & 4 & 81 & 21 \\
\hline Medinaceli & - & 5 & 8 & 7 & 6 & 3 & 29 & 8 \\
\hline Soria & 10 & 21 & 35 & 23 & 31 & 16 & 136 & 35 \\
\hline Totales & 28 & 72 & 88 & 88 & 80 & 30 & 386 & 100 \\
\hline
\end{tabular}

Fuente: Archivo Histórico Provincial de Soria, Signaturas 7965 y 7966. Audiencia Provincial de

Soria. Libros de Sentencias. Libros núms. 57 a 62. Elaboración propia.

Cuadro 3. Número de condenados/as y absueltos/as por la Audiencia Provincial de Soria (1931-1936) ${ }^{66}$.

Tribunal de Derecho y Tribunal de Urgencia.

\begin{tabular}{|c|c|c|c|c|c|c|c|c|c|c|c|c|c|c|c|c|}
\hline & \multicolumn{2}{|c|}{1931} & \multicolumn{2}{|c|}{1932} & \multicolumn{2}{|c|}{1933} & \multicolumn{2}{|c|}{1934} & \multicolumn{2}{|c|}{1935} & \multicolumn{2}{|c|}{1936} & \multicolumn{2}{|c|}{ Totales } & \multicolumn{2}{|c|}{$\%$ totales } \\
\hline & $V$ & $M$ & $V$ & $\bar{M}$ & $V$ & $M$ & V & $M$ & V & $\bar{M}$ & $V$ & $M$ & $V$ & $M$ & $\bar{V}$ & $M$ \\
\hline Condenados/as & 20 & 1 & 58 & 4 & 57 & 7 & 79 & 4 & 68 & 6 & 19 & 5 & 301 & 27 & 59 & 6 \\
\hline Absueltos/as & 7 & 3 & 33 & 5 & 31 & 8 & 48 & 4 & 19 & 1 & 21 & 0 & 159 & 21 & 31 & 4 \\
\hline Parciales por sexo & 27 & 4 & 91 & 9 & 88 & 15 & 127 & 8 & 87 & 7 & 40 & 5 & 460 & 48 & 90 & 10 \\
\hline Totales & & & & & & & 1 & & & & & & & & & \\
\hline
\end{tabular}

(V, varón; $\mathrm{M}$, mujer)

Fuente: Archivo Histórico Provincial de Soria, Signaturas 7965 y 7966. Audiencia Provincial de Soria. Libros de Sentencias. Libros núms. 57 a 62. Elaboración propia.

En la primera hoja de todas y cada una de las sentencias penales originales, además de la composición de La Sala, al margen izquierdo, formada por sus tres miembros (con el presidente en primer lugar y con los otros dos magistrados por orden de antigüedad), consta una estampilla con el siguiente texto en las sentencias del año 1931: "En cumplimiento de lo ordenado en Orden de 29 de marzo de 1937, en el día de hoy se procedió al expurgo de la causa a que se refiere esta sentencia. Junio 1937". A partir de 1932 consta inserta en las sentencias la siguiente estampilla: "En cumplimiento de lo dispuesto por Orden Ministerial de 30 de julio de 1960, la Junta de Expurgo de esta Audiencia acordó en sesión de hoy declarar inútil el legajo correspondiente en la causa a que se refiere la presente sentencia. Soria, 15 de mayo de $1961 "{ }^{67}$. En su virtud, no se conservan expedientes

${ }^{64}$ El Decreto de 10 de septiembre de 1931 (Gaceta de Madrid núm. 254 de 11 de septiembre de 1931, pp. 17641766), suprimió las cárceles de partido de Ágreda, El Burgo de Osma y Medinaceli, por lo que a partir de entonces, Soria contaría con la prisión provincial, sita en el mismo edificio que la Audiencia Provincial y el Juzgado de Instrucción (en la plaza Mayor de Soria), y la cárcel de partido de Almazán.

${ }^{65}$ Desde el 14 de abril de 1931 hasta el 18 de julio de 1936.

${ }^{66}$ Desde el 14 de abril de 1931 hasta el 18 de julio de 1936.

${ }^{67}$ En relación con la evolución histórica de los expurgos judiciales, GOMEZ LOECHES, L., "El expurgo en los archivos judiciales", en La Administración de Justicia en la historia de España, Actas de las III Jornadas de CastillaLa Mancha sobre investigación en archivos, Vol. II, Guadalajara, Junta de Castilla-La Mancha, 1999, pp. 829-849. 
ni legajos de ningún tipo sobre estos procedimientos penales, a excepción de la propia sentencia original y del libro registro de causas penales.

Hasta la Ley de Orden Público de 1933, el único procedimiento penal de que conocía la Audiencia Provincial de Soria era el sumario ordinario a través del Tribunal de Derecho ${ }^{68}$, teniendo siempre como base procesal la propia Ley de Enjuiciamiento Criminal de 1882. A partir de la entrada en vigor de la Ley de Orden Público, también se formaría el Tribunal de Urgencia para determinados delitos y en determinadas circunstancias (declarado previamente el estado de prevención o de alarma), dentro del mismo ámbito de actuación de la Audiencia y con los mismos componentes de Sala, aunque el procedimiento estaba dotado de mayor celeridad que el ordinario. Así, con el Decreto de 9 de diciembre de 1933 (estado de alarma), el 17 de diciembre de 1933 se dictó la primera sentencia en Soria por el Tribunal de Urgencia. ${ }^{69}$

Del total de sentencias penales dictadas por la Audiencia Provincial de Soria (386), 326 lo serían por el Tribunal de Derecho (85\%) y 60 por el Tribunal de Urgencia (15\%). El año con más sentencias dictadas por el Tribunal de Urgencia fue 1935, con 30 sentencias, seguido de 1934 con 25.70

En un total de 154 pueblos de la provincia de Soria se cometieron delitos con incoación del correspondiente procedimiento penal, y que posteriormente diera lugar a sentencia dictada por la Audiencia Provincial de Soria (Tribunal de Derecho y Tribunal de Urgencia). En relación con el total de 386 sentencias dictadas, en orden decreciente por el número de ellas en las que constara en los hechos probados la comisión del hecho delictivo en cada localidad, las 10 primeros poblaciones de la provincia fueron las siguientes: Soria (54), Almazán (21), Ágreda (20), El Burgo de Osma (19), San Esteban de Gormaz (10), Fuentelmonge (9), Arcos de Jalón (6) y Ciria, Deza y Rebollo de Duero (5). Como dato curioso, sólo consta una sentencia dictada por la Audiencia Provincial de Soria por hechos delictivos cometidos en Medinaceli, cabeza del partido judicial del mismo nombre. ${ }^{71}$

${ }^{68}$ Como hemos dicho, a salvo el Tribunal del Jurado analizado en el siguiente epígrafe.

${ }^{69}$ Sentencia condenatoria núm. 86/1933 de 17 de diciembre, sobre tenencia ilícita de armas en la localidad de Ciria. La prensa soriana de la época se hico eco de las distintas situaciones generadas con las declaraciones de los estados de prevención, alarma y guerra (así, El Avisador Numantino de 13 de diciembre de 1933 "se declara el estado de alarma", de 27 de junio de 1934 "cesan el estado de alarma y la censura", y de 10 de diciembre de 1934 “el gobierno declara el estado de alarma en toda la nación”). Con respecto a la Ley de Orden Público, al Tribunal de Urgencia y a los estados de prevención, alarma y guerra, puede verse PAYÁ POVEDA, J.M., Justicia, orden público y Tribunales de Urgencia en la II República, Cizur Menor (Navarra), Thomson Reuters, Aranzadi, 2017. También, aunque más referido a la violencia y al deterioro del orden público, GONZÁLEZ CALLERA, E., COBO ROMERO, F., MARTÍNEZ RUS, A., y SÁNCHEZ PÉREZ, F., La Segunda República Española..., op. cit., pp. 884-892 y 1129-1149.

${ }^{70}$ Los delitos más habituales conocidos por el Tribunal de Urgencia fueron los de tenencia ilícita de armas de fuego y atentado contra agente de la autoridad. Por su parte, el Tribunal de Derecho conocería fundamentalmente de hurtos, lesiones, imprudencia temeraria y robos (véase cuadro elaborado al respecto).

71 Archivo Histórico Provincial de Soria, signaturas 7965 y 7966. Audiencia Provincial de Soria. Libros de Sentencias. Libros núms. 57 a 62. A continuación se reflejan detalles de algunas de ellas de forma sucinta y cronológica: primera sentencia dictada por la Audiencia Provincial de Soria en la II República, hurto de prendas de lavar en Fuentelmonge -Sala formada por José María Rodríguez del Valle, presidente, y José Boza Moreno y Enrique Cerezo Cardona, magistrados- (sentencia condenatoria de 28 de abril de 1931); homicidio por imprudencia en Borobia, al instalar un transformador sin título ni pericia alguna y producir una descarga eléctrica a una vecina del pueblo que falleció en el acto en su propia casa por derivación de corriente (sentencia absolutoria de 30 de octubre de 1931); homicidio por imprudencia en Deza cuando el coche del procesado, médico, chocó con un niño que salía de una calleja del pueblo con la parte trasera del coche (sentencia absolutoria de 30 de septiembre de 1932); injurias a la Autoridad por publicar un artículo en el periódico semanal de Soria "Trabajo" contra el 
Cuadro 4. Número de sentencias dictadas por la Audiencia Provincial de Soria clasificadas por delitos según la expresión del Fallo de la misma (1931-1936) ${ }^{72}$. Desglose entre el Tribunal de Derecho y el Tribunal de Urgencia.

TU (Tribunal de Urgencia)

\begin{tabular}{|c|c|c|c|c|c|c|c|c|c|c|c|c|c|c|c|}
\hline \multirow{2}{*}{ Delito/Año } & \multicolumn{2}{|c|}{1931} & \multicolumn{2}{|c|}{1932} & \multicolumn{2}{|c|}{1933} & \multicolumn{2}{|c|}{1934} & \multicolumn{2}{|c|}{1935} & \multicolumn{2}{|c|}{1936} & \multicolumn{2}{|c|}{ Parciales } & \multirow[t]{2}{*}{ Totales } \\
\hline & & $T U$ & & $T U$ & & $T U$ & & $T U$ & & $T U$ & & $T U$ & & $T U$ & \\
\hline & & & & & & & & & & & & & & & \\
\hline $\begin{array}{l}\text { Allanamiento de } \\
\text { morada }\end{array}$ & - & - & 1 & - & - & - & 1 & - & 1 & - & - & - & 3 & - & 3 \\
\hline $\begin{array}{c}\text { Alzamiento de } \\
\text { bienes }\end{array}$ & 1 & - & - & - & - & - & - & - & - & - & - & - & 1 & - & 1 \\
\hline $\begin{array}{c}\text { Amenazas agente } \\
\text { autoridad }\end{array}$ & 1 & - & 2 & - & 1 & - & 2 & 1 & 1 & 3 & - & - & 7 & 4 & 11 \\
\hline $\begin{array}{c}\text { Atentado agente } \\
\text { autoridad }\end{array}$ & 1 & - & 6 & - & 3 & - & 1 & 4 & - & 3 & - & - & 11 & 7 & 18 \\
\hline Coacciones & - & - & - & - & - & - & 1 & 1 & - & - & - & - & 1 & 1 & 2 \\
\hline Daños & - & - & 1 & - & 1 & - & 1 & - & - & - & 1 & - & 4 & - & 4 \\
\hline Desacato & - & - & 2 & - & 4 & - & 2 & 2 & - & - & - & - & 8 & 2 & 10 \\
\hline Desobediencia & - & - & - & - & 1 & - & 4 & - & 2 & - & 1 & - & 8 & - & 8 \\
\hline $\begin{array}{l}\text { Desórdenes } \\
\text { públicos }\end{array}$ & - & - & - & - & - & - & 1 & - & - & - & - & - & 1 & - & 1 \\
\hline $\begin{array}{l}\text { Disparo de arma de } \\
\text { fuego }\end{array}$ & - & - & 2 & - & 1 & - & - & - & - & - & - & - & 3 & - & 3 \\
\hline $\begin{array}{l}\text { Ejercicio ilegal de } \\
\text { funciones }\end{array}$ & - & - & - & - & 1 & - & - & - & - & - & - & - & 1 & - & 1 \\
\hline Estafa & 5 & - & 8 & - & - & - & 1 & - & 2 & - & 1 & - & 17 & - & 17 \\
\hline Estupro & 1 & - & 1 & - & 1 & - & - & - & - & - & - & - & 3 & - & 3 \\
\hline Falsedad & - & - & 1 & - & 1 & - & - & - & - & - & - & - & 2 & - & 2 \\
\hline Homicidio & 1 & - & 3 & - & 1 & - & - & - & - & 5 & - & - & 5 & 5 & 10 \\
\hline Hurto & 4 & - & 15 & - & 14 & - & 14 & - & 14 & - & 8 & - & 69 & - & 69 \\
\hline $\begin{array}{c}\text { Imprudencia } \\
\text { temeraria }\end{array}$ & - & - & - & - & 10 & - & 10 & - & 3 & - & 2 & - & 25 & - & 25 \\
\hline Incendio & - & - & 2 & - & - & - & - & - & 1 & - & - & - & 3 & - & 3 \\
\hline $\begin{array}{c}\text { Infracción a la ley de } \\
\text { caza }\end{array}$ & - & - & 2 & - & 4 & - & 1 & - & 3 & - & 2 & - & 12 & - & 12 \\
\hline $\begin{array}{c}\text { Infracción a la ley de } \\
\text { pesca }\end{array}$ & - & - & 1 & - & 1 & - & - & - & - & - & - & - & 2 & - & 2 \\
\hline $\begin{array}{c}\text { Injurias agente } \\
\text { autoridad }\end{array}$ & 2 & - & 3 & - & 8 & - & 2 & - & - & 4 & 1 & 1 & 16 & 5 & 21 \\
\hline $\begin{array}{c}\text { Insolvencia } \\
\text { culpable/fraudulenta }\end{array}$ & - & - & - & - & - & - & - & - & 2 & - & - & - & 2 & - & 2 \\
\hline Lesiones & 4 & - & 14 & - & 19 & - & 11 & - & 14 & 4 & 3 & - & 65 & 4 & 69 \\
\hline
\end{tabular}

gobierno de Azaña, presidente del gobierno, y Quiroga, ministro de la gobernación (sentencia condenatoria de 17 de marzo de 1933); injurias a la Autoridad con motivo de la publicación de un artículo en el periódico semanal de Soria "Trabajo", con el título "Bajo la Dictadura de Puig Espert" y "Ante una posible tragedia", artículos injuriosos para el gobernador civil (sentencia condenatoria de 13 de junio de 1933); imprudencia temeraria al fallecer un niño por electrocución al tocar un poste metálico cerca del puente de hierro del ferrocarril en Almazán (sentencia condenatoria de 24 de febrero de 1934); atentado a un agente de la autoridad al acudir a un tumulto en el prostíbulo conocido como "Casa de la Charo" en el Paseo de la Florida de Soria (sentencia condenatoria de 16 de junio de 1934); insultos al ministro de la República Alejandro Lerroux cuando el procesado se hallaba en el casino de la Amistad de Soria en estado de embriaguez (sentencia condenatoria de 24 de febrero de 1935); homicidio en Sauquillo de Alcazar cuando el condenado disparó con una escopeta a unos vecinos que daban una cencerrada frente a la casa de su suegro, causándole la muerte a uno de ellos (sentencia condenatoria de 20 de julio de 1935); última sentencia de la Audiencia Provincial de Soria en la II República (Tribunal de Urgencia), por tenencia ilícita de armas de fuego, al ocuparse a un vecino de La Miñosa una pistola sin la oportuna guía y licencia -Sala formada por Fermín Lozano Contra, presidente, y Jesús Urrutia Castillo y Fructuoso Cid Abad, magistrados- (sentencia condenatoria de 15 de julio de 1936).

${ }^{72}$ Desde el 14 de abril de 1931 hasta el 18 de julio de 1936. 


\begin{tabular}{|c|c|c|c|c|c|c|c|c|c|c|c|c|c|c|c|}
\hline $\begin{array}{c}\text { Levantamiento de } \\
\text { embargo }\end{array}$ & - & - & - & - & - & - & - & - & - & - & 1 & - & 1 & - & 1 \\
\hline Prevaricación & 1 & - & - & - & - & - & - & - & - & - & - & - & 1 & - & 1 \\
\hline $\begin{array}{c}\text { Resistencia a la } \\
\text { autoridad }\end{array}$ & 1 & - & - & - & 4 & - & - & 1 & - & 3 & - & - & 5 & 4 & 9 \\
\hline Robo & 4 & - & 3 & - & 5 & - & 6 & - & 3 & - & 5 & - & 26 & - & 26 \\
\hline $\begin{array}{l}\text { Tenencia de } \\
\text { explosivos }\end{array}$ & - & - & - & - & - & - & 1 & 1 & - & - & - & - & 1 & 1 & 2 \\
\hline $\begin{array}{l}\text { Tenencia ilícita de } \\
\text { arma de fuego }\end{array}$ & 1 & - & 5 & - & 7 & 1 & 4 & 14 & 3 & 9 & - & 3 & 20 & 27 & 47 \\
\hline $\begin{array}{c}\text { Uso de nombre } \\
\text { supuesto }\end{array}$ & 1 & - & - & - & - & - & - & - & - & - & 1 & - & 2 & - & 2 \\
\hline $\begin{array}{c}\text { Usurpación de } \\
\text { atribuciones }\end{array}$ & - & - & - & - & - & - & 1 & - & - & - & - & - & 1 & - & 1 \\
\hline Parciales & 28 & - & 72 & - & 87 & 1 & 63 & 25 & 50 & 30 & 26 & 4 & 326 & 60 & 386 \\
\hline TOTALES & & & & & & & & & & & & & & & \\
\hline
\end{tabular}

Fuente: Archivo Histórico Provincial de Soria, Signaturas 7965 y 7966. Audiencia Provincial de Soria. Libros de Sentencias. Libros núms. 57 a 62. Elaboración propia.

\section{III.2.2.1.2. Tribunal del Jurado}

El Decreto de 27 de abril de 1931 restableció el Jurado conforme a su Ley de 20 de abril de 1888. En cuanto al tamaño y composición del Tribunal, la Sección de Hecho se redujo de 12 a 8 jurados, mientras que la Sección de Derecho de la misma permaneció invariable (los tres magistrados de la propia Audiencia Provincial). Tras la modificación introducida por el Decreto de 22 de septiembre de 1931, la compleja maquinaria sobre el sorteo de Jurados por cuatrimestres y partidos judiciales, así como la correspondiente vista oral y posterior veredicto, la primera sentencia del Tribunal del Jurado en Soria en la II República se dictó el 26 de enero de 1932.73

Hasta el 18 de julio de 1936, el Tribunal del Jurado de Soria dictó un total de 39 sentencias. Además, se dictaron 4 autos de sobreseimiento libre. El año en el que más sentencias se dictaron por esta Institución fue 1933 con 18 sentencias. En cuanto al número total de enjuiciados por Jurado, el mismo ascendió a 57 personas, de las cuales 51 fueron varones y 6 mujeres. Del total de enjuiciados, 26 fueron condenados (45\%) y 31 absueltos (55\%). Los delitos más habituales que dieran lugar a sentencia del Tribunal del Jurado en Soria fueron los homicidios y las violaciones.

Cuadro 5. Sentencias penales dictadas por el Tribunal del Jurado de Soria durante la II República según el partido judicial de procedencia (instrucción). 1932-1936.

\begin{tabular}{|c|c|c|c|c|c|c|c|c|c|}
\hline Partido Judicial/Año & 1931 & 1932 & 1933 & 1934 & 1935 & 1936 & Totales & & $\%$ \\
\hline Agreda & & 2 & 3 & - & 1 & - & 6 & & 15 \\
\hline Almazán & & - & 3 & 2 & - & - & 5 & 13 \\
\hline El Burgo de Osma & & - & 5 & 1 & 4 & 2 & 12 & 30 \\
\hline Medinaceli & & - & 1 & - & 1 & - & 2 & & 5 \\
\hline Soria & & 2 & 6 & 2 & 3 & 1 & 14 & 37 \\
\hline Totales & & 4 & 18 & 5 & 9 & 3 & 39 & 100 \\
\hline
\end{tabular}

Fuente: Archivo Histórico Provincial de Soria, Signaturas 7965 y 7966 . Audiencia Provincial de Soria. Libros de Sentencias. Libros núms. 57 a 62. Elaboración propia.

\footnotetext{
${ }^{73}$ La instrucción de la causa corrió a cargo del Juzgado de Primera Instancia e Instrucción de Ágreda, con sentencia condenatoria núm. 1/1932, de 26 de enero, del Tribunal del Jurado de Soria (homicidio ocurrido en Cueva de Ágreda). Con respecto al Tribunal del Jurado en la II República, MARÉS ROGER, F., "El Tribunal del Jurado en la II República española", en Boletín de Información del Ministerio de Justicia, año XLIX, núm. 1760, noviembre 1995, pp. 95-113.
} 
Cuadro 6. Número de condenados/as y absueltos/as durante la II República por el Tribunal del Jurado de Soria (1932-1936).

\begin{tabular}{|c|c|c|c|c|c|c|c|c|c|c|c|c|c|c|c|c|}
\hline & \multicolumn{2}{|c|}{1931} & \multicolumn{2}{|c|}{1932} & \multicolumn{2}{|c|}{1933} & \multicolumn{2}{|c|}{1934} & \multicolumn{2}{|c|}{1935} & \multicolumn{2}{|c|}{1936} & \multicolumn{2}{|c|}{ Totales } & \multicolumn{2}{|c|}{$\%$ totales } \\
\hline & $V$ & $M$ & $\bar{V}$ & $M$ & V & $M$ & $\bar{V}$ & $M$ & $\bar{V}$ & $M$ & $V$ & $M$ & V & $M$ & V & $M$ \\
\hline Condenados/as & & & 3 & - & 8 & 2 & 4 & 1 & 6 & - & 2 & - & 23 & 3 & 40 & 5,5 \\
\hline Absueltos/as & & & 1 & - & 15 & 3 & 1 & - & 4 & - & 7 & - & 28 & 3 & 49 & 5,5 \\
\hline $\begin{array}{c}\text { Parciales por } \\
\text { sexo }\end{array}$ & & & 4 & - & 23 & 5 & 5 & 1 & 10 & - & 9 & - & 51 & 6 & 89 & 11 \\
\hline Totales & & & & 7 & & & & & & & & 9 & & & & \\
\hline
\end{tabular}

(V, varón; $\mathrm{M}$, mujer)

Fuente: Archivo Histórico Provincial de Soria, Signaturas 7965 y 7966. Audiencia Provincial de Soria. Libros de Sentencias. Libros núms. 57 a 62. Elaboración propia.

Cuadro 7. Número de sentencias dictadas durante la II República por el Tribunal del Jurado de Soria clasificadas por delitos según la expresión del Fallo de la misma (1932-1936).

\begin{tabular}{|c|c|c|c|c|c|c|c|c|}
\hline Delito/Año & 1931 & 1932 & 1933 & 1934 & 1935 & 1936 & Totales & $\%$ \\
\hline Abusos deshonestos & & - & 1 & - & 2 & - & 3 & 7,6 \\
\hline Asesinato & & 1 & 1 & 1 & - & - & 3 & 7,6 \\
\hline Cohecho & & - & - & - & - & 1 & 1 & 2,5 \\
\hline Detención ilegal & & - & 1 & - & - & - & 1 & 2,5 \\
\hline Homicidio & & 2 & 7 & 2 & 2 & - & 13 & 33,3 \\
\hline Imprudencia temeraria & & - & - & - & 1 & - & 1 & 2,5 \\
\hline Infanticidio & & - & 2 & 1 & - & - & 3 & 7,6 \\
\hline Lesiones & & - & - & - & 1 & - & 1 & 2,5 \\
\hline Parricidio & & - & 1 & - & - & - & 1 & 2,5 \\
\hline Tenencia de explosivos & & - & 1 & - & - & - & 1 & 2,5 \\
\hline Uso de armas sin licencia & & - & 1 & - & - & - & 1 & 2,5 \\
\hline Violación & & 1 & 3 & 1 & 3 & 2 & 10 & 25,6 \\
\hline & & & & & & & & \\
\hline Totales & & 4 & 18 & 5 & 9 & 3 & 39 & 100 \\
\hline
\end{tabular}

Fuente: Archivo Histórico Provincial de Soria, Signaturas 7965 y 7966. Audiencia Provincial de Soria. Libros de Sentencias. Libros núms. 57 a 62. Elaboración propia.

En un total de 34 pueblos de la provincia de Soria se cometieron delitos con incoación del correspondiente procedimiento penal que posteriormente diera lugar a sentencia de la Audiencia Provincial de Soria como Tribunal del Jurado (39 sentencias). En orden decreciente por el número de sentencias dictadas en las que consta en el veredicto del Jurado la comisión del hecho delictivo en dicha localidad, las 4 primeras fueron las siguientes: El Burgo de Osma y Deza (3), y Osma y Zayas de Torre (2). El resto de pueblos, con 1 sentencia cada uno, fueron los siguientes: Ágreda, Almarail, Almazán, Benamira, Berlanga de Duero, Buimanco, Castilruiz, Chavaler, Chércoles, Cihuela, Covaleda, Cuevas de Ágreda, Duañez, Gómara, Herreros, La Alameda, La Muedra, La Olmeda, Mazalvete, Montejo de Liceras, Morón de Almazán, Noviercas, Retortillo, Riba de Escalote, San Leonardo, Santa María de Huerta, Tarancueña, Tardelcuende y Valtajeros. ${ }^{74}$

74 Archivo Histórico Provincial de Soria, signaturas 7965 y 7966. Audiencia Provincial de Soria. Libros de Sentencias. Libros núms. 57 a 62. A continuación se reflejan detalles de algunas de ellas de forma sucinta y cronológica: la primera sentencia del Tribunal del Jurado de Soria (como ya se ha indicado), fue de fecha 26 de enero de 1932, por homicidio en Cueva de Ágreda; asesinato en Valtajeros al disparar un tiro de pistola contra una joven de 16 años (sentencia condenatoria de 4 de junio de 1932 -atenuante de deficiencia mental-); auto de sobreseimiento de 25 de julio de 1933 con respecto a varios procesados, en relación con la explosión de una bomba en el viaducto de la línea de enlace del ferrocarril Soria-Castejón; asesinato en una taberna de Osma, en 


\section{III.2.2.1.3. Vagos y maleantes}

Con la Ley de Vagos y Maleantes de 1933, podían ser declarados en estado peligroso y sometidos a determinadas medidas de seguridad, entre otros, los vagos habituales, los rufianes y proxenetas, los mendigos profesionales, los ebrios y toxicómanos habituales (art. 2). Las medidas de seguridad que podían ser aplicadas por los tribunales, y que tenían que cumplirse inmediatamente después de extinguir las penas aplicadas por el delito o delitos sancionados, eran, entre otras, internamiento en un establecimiento en régimen de trabajo o colonias agrícolas, internamiento en un establecimiento de custodia, aislamiento curativo en Casas de templanza, sumisión a la vigilancia de la autoridad y multa (art. 4).

En el momento en el que un tribunal penal dictara una sentencia por delito contra un reincidente o reiterante en el que fuera presumible la habitualidad criminal o contra un reo que se estimara peligroso, se aplicarían de oficio la medida o medidas de seguridad correspondientes, haciéndolas constar en fallo separado del principal (art. 9). ${ }^{75}$

La Audiencia Provincial de Soria, constituida en Tribunal conforme a la Ley de Vagos y Maleantes, dictó dos sentencias desde la aprobación de la Ley hasta el final de la II República en Soria

la carretera de Valladolid a Soria, al clavar un cuchillo en las costillas de la víctima (sentencia condenatoria de 20 de septiembre de 1933); homicidio al recibir muchos palos un obrero en el pantano de La Cuerda del Pozo, en La Muedra (sentencia condenatoria de 22 de diciembre de 1933, un condenado y ocho absueltos); infanticidio e inhumación ilegal en La Olmeda, al dejar abandonado recién nacido a su hijo vivo y una vez fallecido un familiar cercano proceder a enterrarlo en la cuadra de la casa (sentencia condenatoria de 19 de febrero de 1934); homicidio en Noviercas al golpear a la víctima con un martillo en la cabeza y apoderarse de 17 pesetas de los bolsillos del fallecido, hecho cometido con acuerdo de otra persona (sentencia condenatoria de 28 de marzo de 1935, tratándose de la mayor condena de un tribunal soriano durante la II República -dos condenados a 27 años de reclusión mayor cada uno-); violación en Zayas de Torre (sentencia condenatoria de 26 de marzo de 1936); la última sentencia dictada por el Tribunal del Jurado de Soria durante el período republicano fue con fecha 12 de junio de 1936 (tentativa de violación en Tarancueña, sentencia condenatoria).

En cuanto a la organización de la Justicia en relación con los menores de edad y su responsabilidad penal (tanto el Código Penal de 1928 como el de 1932 señalaban la mayoría de edad penal en 16 años), en Soria, no fue hasta la Orden de 29 de enero de 1941 cuando se nombró presidente y vicepresidente del Tribunal Tutelar de Menores de Soria (Boletín Oficial del Estado de 3 de febrero de 1941), siendo la Orden de 14 de agosto de 1941 la que autorizó la entrada en funcionamiento del Tribunal soriano (Boletín Oficial del Estado de 16 de agosto de 1941). Con anterioridad a dichas fechas, aún cuando en Soria no tuviera efectividad concreta, importante sería el Real Decreto-ley de 3 de febrero de 1929 de organización de los Tribunales Tutelares de Menores (Gaceta de Madrid de 6 de febrero de 1929), y su Reglamento (de la misma fecha y publicación en la Gaceta de Madrid del día siguiente). En relación a la normativa sobre menores con anterioridad a dichas fechas (Juntas Provinciales y Locales de Protección de la Infancia en 1908, Tribunales para Niños en 1918, y Tribunales Tutelares para Niños en 1925), puede verse REVUELTA GUERRERO, R.C., y GALENDE MATEOS, A., "La prehistoria del Tribunal para Niños de Valladolid (1904-1948)", en El largo camino hacia una educación inclusiva: la educación especial y social del siglo XIX a nuestros dias: XV Coloquio de Historia de la Educación, vol. 2, María Reyes Berruezo Albéniz y Susana Conejero López (coordinadoras), Pamplona, Universidad Pública de Navarra, 2009, pp. 311-324; y CID SABUCEDO, A., y SOTO FERNÁNDEZ, J.R., "Evolución de protección de menores en la provincia de Ourense (1936-1960)", en Minius, núm. 15, Universidad de Vigo, 2007, pp. 49-65. También la Memoria elevada al Gobierno de la República con motivo de la solemne apertura de los Tribunales el día 15 de septiembre de 1933 por el Fiscal General de la República, Madrid, Editorial Reus, 1933, pp. 11 y 12.

${ }^{75}$ En relación con la Ley de Vagos y Maleantes en la II República, MARTÍNEZ DHIER, A., “Apuntes sobre la vagancia y su represión durante la II República española: la Ley de Vagos y Maleantes de 1933”, en Represión y Orden Público durante la II República, la Guerra Civil y el Franquismo. Una visión comparada, VVAA, José Antonio Pérez Juan y Sara Moreno Tejada (coordinadores), Cizur Menor (Navarra), Thomson Reuters. Aranzadi, 2019, pp. 59-87. 
(18 de julio de 1936) ${ }^{76}$. En la primera de ellas, de fecha 2 de marzo de 1936, se vio el recurso de apelación contra la sentencia dictada por el Juzgado de Instrucción de Almazán. Un vecino de Madrid fue detenido en Almazán con una baraja. En base a que el mismo había trabajado poco, había ocultado su verdadero nombre, había sido encarcelado varias veces y no se había justificado su medio de vida, el Juzgado de Instrucción dictó sentencia imponiendo al mismo unas medidas de seguridad. Una vez apelada la sentencia de instancia, la Audiencia Provincial como Tribunal declaró al detenido como comprendido en la Ley de Vagos y Maleantes y se impusieron las medidas de seguridad de internamiento en establecimiento de trabajo por tiempo indeterminado que no excedería de tres años y multa de 250 pesetas, así como la destrucción de la baraja intervenida ${ }^{77}$. En la segunda de las sentencias dictadas, de fecha 8 de abril de 1936, el Tribunal (Audiencia Provincial de Soria), vio la causa procedente del Juzgado de Instrucción de Almazán, por sustracción de reses lanares, vino y aperos de labranza, contra un vecino de Berlanga de Duero que había sido condenado previamente por muchos delitos entre 1929 y 1930 (sobre todo contra la propiedad), y después de cumplir sus condenas en el Penal de Burgos, volvió a delinquir, motivando así la formación del sumario. El fallo de la sentencia del Tribunal ${ }^{78}$ declaró al mismo comprendido en los parámetros de la Ley de Vagos y Maleantes de 1933, y se le impuso la medida de seguridad de internamiento en un establecimiento de custodia por tiempo indeterminado que no excedería de dos años, y que cumpliría una vez extinguidas las penas principales impuestas en la sentencia que motivó el Rollo (sentencia de 7 de abril de 1936). ${ }^{79}$

III.2.2.2. Jurisdicción contencioso-administrativa. Tribunal Provincial de lo ContenciosoAdministrativo de Soria

Al comenzar la II República estaba en funcionamiento el Tribunal Provincial de lo Contencioso-Administrativo de Soria bajo los parámetros de la propia Audiencia Provincial de Soria ${ }^{80}$. Este Tribunal estaba constituido por cinco miembros: tres magistrados que lo eran los de la

\footnotetext{
76 Archivo Histórico Provincial de Soria, Audiencia Provincial de Soria, signatura 7966, libro 62.

${ }^{77}$ La Sala estaba formada por Fermín Lozano Contra, presidente, y Jesús Urrutia Castillo y Fructuoso Cid Abad, magistrados.

${ }^{78}$ La Sala estaba formada por Fermín Lozano Contra, presidente, y Jesús Urrutia Castillo y Eduardo Peña Martínez, magistrados (este último magistrado suplente).

${ }^{79} \mathrm{Al}$ final de esta sentencia de la Audiencia Provincial de Soria que inició el procedimiento comprendido en la Ley de Vagos y Maleantes de 1933 (sentencia núm. 14/36, de 7 de abril de 1936), se hacía constar el siguiente párrafo: "Tráiganse los autos a la vista para dictar inmediatamente sentencia respecto a la aplicación de la Ley de Vagos y Maleantes al procesado, solicitado por el Ministerio Fiscal”. Archivo Histórico Provincial de Soria, Audiencia Provincial de Soria, signatura 7966, libro 62. Con posterioridad al 18 de julio de 1936, antes de finalizar el referido año, se dictó en Soria una tercera sentencia en relación con la Ley de Vagos y Maleantes: fue la sentencia de fecha 31 de diciembre de 1936 (en cuyos hechos probados consta una persona, vecina de Borja, que se hacía pasar por hermano político del teniente-coronel de la Guardia Civil y, obteniendo la confianza de distintos establecimientos de la ciudad de Soria, no abonaba los servicios prestados por los mismos, como eran hospedaje, talleres, préstamos...). Después, ya en el año 1945, consta una sentencia dictada con fecha 21 de abril de 1945, en relación con la Ley de Vagos y Maleantes. Archivo Histórico Provincial de Soria, Audiencia Provincial de Soria, signatura 7966, libro 62.

${ }^{80} \mathrm{Y}$ así lo hacía desde la entrada en vigor de la Ley de 13 de septiembre de 1888 sobre el ejercicio de la Jurisdicción Contencioso-Administrativa (Gaceta de Madrid núm. 258 de 14 de septiembre de 1888), reformada en parte por el Real Decreto de 22 de junio de 1894 (Gaceta de Madrid núm. 183 de 2 de julio de 1894). Bastante tiempo después, en 1952, el Decreto de 8 de febrero aprobó el texto refundido de la Ley de lo ContenciosoAdministrativo (Boletín Oficial del Estado núm. 76 de 16 de marzo), hasta la aprobación de la nueva Ley reguladora de la Jurisdicción Contencioso-Administrativa de 27 de diciembre de 1956 (Boletín Oficial del Estado núm. 363 de 28 de diciembre de 1956).
} 
propia Audiencia y otros dos miembros no judiciales. El tribunal soriano conocía de las demandas que como recursos contencioso-administrativos se entablaran contra las resoluciones administrativas de las autoridades provinciales y municipales de la provincia soriana. ${ }^{81}$

El Tribunal Provincial de lo Contencioso-Administrativo de Soria dictó durante la II República un total de 49 sentencias, siendo 1933 el año con mayor número de ellas (14). Del total de las mismas, 24 fueron revocatorias (49\%), 17 confirmatorias (35\%) y 8 lo fueron por incompetencia de jurisdicción (16\% del total). En cuanto al recurso en sí (al acuerdo administrativo que se recurría), la inmensa mayoría (39 de las 49 sentencias dictadas, es decir, un $80 \%$ del total) lo fueron contra acuerdos de ayuntamientos de la provincia, sobre todo acuerdos en relación con nombramientos de personal, distribución y aprovechamientos de bienes comunales, aspectos económicos de sueldos y pensiones, y acuerdos sobre obras. En concreto, serían los siguientes ayuntamientos: El Burgo de Osma (2), Navaleno, Ágreda, Castillejo de Robledo (3), Cabrejas del Pinar (2), Ólvega, Fuentetoba, Villaciervos, Espeja de San Marcelino (2), Maján, Arcos de Jalón, Salinas de Medinaceli, Valderromán, Covaleda, Montejo de Liceras, Baraona, Alcozar, Villaverde del Monte, Soria (2), Langa de Duero (2), La Alameda, Matasejún, Gallinero (2), Osma, Almazán, Vinuesa, Duruelo de la Sierra, El Royo y Vozmediano (2). El resto de demandas, en forma de recursos contencioso-administrativos, lo serían contra acuerdos del Tribunal Económico-Administrativo de Soria, de la Delegación de Hacienda de Soria, de las Comisiones representantes de pueblos (zonas médicas de Soria), de la Comisión gestora de la Diputación Provincial de Soria y de la Cámara Oficial de la propiedad urbana de Soria. ${ }^{82}$

En la prensa soriana de la época y en el Boletín Oficial de la Provincia, se insertaba continuamente información sobre la constitución del Tribunal Provincial de lo ContenciosoAdministrativo de Soria, así como anuncios que versaban sobre la publicidad de la interposición de un determinado recurso para conocimiento de cuantos tuvieran interés directo en el asunto y para quienes quisieran coadyuvar en él con la administración. ${ }^{83}$

${ }^{81}$ Sobre la jurisdicción contencioso-administrativa y sus sucesivas reformas a lo largo del tiempo, GONZÁLEZ PÉREZ, J., "Evolución de la legislación contencioso-administrativa", en Revista de Administración Pública, núm. 150, septiembre-diciembre 1999, pp. 209-237.

${ }^{82} \mathrm{La}$ Sala del Tribunal de lo Contencioso-Administrativo de Soria durante el período republicano, conforme a las sentencias dictadas por el mismo y sus correspondientes fechas y encabezamientos concretos, fue la siguiente: desde el 12 de noviembre de 1931 (primera sentencia dictada durante el período republicano), José Boza Moreno, presidente, Fermín Lozano Contra e Ignacio Infante Pérez, vocales magistrados, y Joaquín Orense Talavera y José Tudela de la Orden, vocales no magistrados; desde el 28 de marzo de 1933, Manuel Vicente Tutor y Guelbenzu, presidente, Jesús Urrutia Castillo y Eduardo Peña Martínez, vocales judiciales, y Joaquín Orense Talavera y Blas Taracena Aguirre, vocales no judiciales; desde el 15 de enero de 1935, Fructuoso Cid Abad, presidente, Jesús Urrutia Castillo y Eduardo Peña Martínez, vocales judiciales, y Blas Taracena Aguirre y Félix García-Baquero y García-Baquero, vocales no judiciales; y desde el 18 de noviembre de 1935, Fermín Lozano Contra, presidente, Jesús Urrutia Castillo y Fructuoso Cid Abad, vocales judiciales, y Blas Taracena Aguirre y Félix García-Baquero y García-Baquero, vocales no judiciales. La última sentencia en período republicano se dictó en Soria por su Tribunal Provincial de lo Contencioso-Administrativo con fecha 15 de julio de 1936. Con posterioridad, hasta finales de 1936 no se dictó ninguna sentencia (la siguiente sería ya en 1937). Archivo Histórico Provincial de Soria, signatura 7977. Audiencia Provincial de Soria. Libros de Sentencias. Libro núm. 96.

${ }^{83}$ Así, El Avisador Numantino de 31 de octubre de 1931 y el Boletín Oficial de la Provincia de Soria de 25 de enero de 1932. También se anunciaban las personas capacitadas para formar parte como vocales no judiciales en el próximo quinquenio del Tribunal Provincial de lo Contencioso-Administrativo de Soria, como en los Boletines Oficiales de la Provincia de Soria de 14 de abril de 1933 (Joaquín Orense Talavera y Blas Taracena Aguirre), y de 21 de noviembre de 1934 (Félix García-Baquero y García-Baquero). 
Cuadro 8. Sentencias dictadas por el Tribunal Provincial de lo Contencioso-Administrativo de Soria según el Fallo de la misma (1931-1936) ${ }^{84}$

\begin{tabular}{|c|c|c|c|c|c|c|c|c|}
\hline Parte Dispositiva/Año & 1931 & 1932 & 1933 & 1934 & 1935 & 1936 & Totales & $\%$ \\
\hline Revocatorias & 1 & 5 & 4 & 4 & 2 & 8 & 24 & 49 \\
\hline Confirmatorias & 1 & 1 & 7 & 3 & 3 & 2 & 17 & 35 \\
\hline $\begin{array}{l}\text { Incompetencia de } \\
\text { Jurisdicción }\end{array}$ & - & - & 3 & - & 3 & 2 & 8 & 16 \\
\hline Totales & 2 & 6 & 14 & 7 & 8 & 12 & 49 & 100 \\
\hline
\end{tabular}

Fuente: Archivo Histórico Provincial de Soria, signatura 7977. Audiencia Provincial de Soria. Libros de Sentencias. Libro núm. 96. Elaboración propia.

Cuadro 9. Sentencias dictadas por el Tribunal Provincial de lo Contencioso-Administrativo de Soria durante la II República, ordenadas conforme al contenido del recurso interpuesto (1931-1936)

\begin{tabular}{|c|c|c|c|c|c|c|c|c|}
\hline Recurso contra acuerdos de & 1931 & 1932 & 1933 & 1934 & 1935 & 1936 & Totales & $\%$ \\
\hline $\begin{array}{c}\text { Ayuntamientos de } \\
\text { la provincia de Soria }\end{array}$ & 2 & 6 & 9 & 7 & 5 & 10 & 39 & 80 \\
\hline $\begin{array}{c}\text { Tribunal } \\
\text { Económico-Administrativo } \\
\text { de Soria }\end{array}$ & - & - & 3 & - & 2 & - & 5 & 10 \\
\hline $\begin{array}{c}\text { Delegación de Hacienda de } \\
\text { Soria }\end{array}$ & - & - & 1 & - & - & - & 1 & 2 \\
\hline $\begin{array}{c}\text { Comisiones representantes } \\
\text { de pueblos (zonas médicas } \\
\text { de Soria) }\end{array}$ & - & - & 1 & - & - & - & 1 & 2 \\
\hline $\begin{array}{c}\text { Comisión gestora de la } \\
\text { Diputación Provincial de } \\
\text { Soria }\end{array}$ & - & - & - & - & 1 & 1 & 2 & 4 \\
\hline $\begin{array}{c}\text { Cámara Oficial de la } \\
\text { propiedad urbana de Soria }\end{array}$ & - & - & - & - & - & 1 & 1 & 2 \\
\hline Totales & 2 & 6 & 14 & 7 & 8 & 12 & 49 & 100 \\
\hline
\end{tabular}

Fuente: Archivo Histórico Provincial de Soria, signatura 7977. Audiencia Provincial de Soria. Libros de Sentencias. Libro núm. 96. Elaboración propia.

\section{III.2.2.3. Jurisdicción civil. Divorcios}

Con la aprobación de la Ley del Divorcio de 2 de marzo de 1932, la Audiencia Provincial de Soria asumió las competencias para conocer las disoluciones del matrimonio cuando lo solicitara cualquiera de los cónyuges por alguna de las causas recogidas en la propia ley. ${ }^{85}$

En su virtud, la Audiencia soriana comenzó a conocer de asuntos de divorcio vincular y separación de personas y bienes, dictando la primera sentencia con fecha 23 de julio de 1932 de un asunto procedente en instrucción del Juzgado de Primera Instancia e Instrucción de El Burgo de Osma. En total, hasta el 18 de julio de 1936, la Audiencia Provincial de Soria dictó un total de 17 sentencias al respecto (15 sobre divorcio y 2 sobre separación). De las referidas 15 en relación al divorcio, 13 fueron estimatorias, habiendo lugar al divorcio ( 7 en las que era demandante el marido y 6 en las que la demanda la presentó la mujer), y 2 fueron desestimatorias, acordando no haber lugar

\footnotetext{
${ }^{84}$ Desde el 14 de abril de 1931 hasta el 18 de julio de 1936.

${ }^{85}$ En el caso de que lo solicitaran ambos cónyuges de mutuo acuerdo (mutuo disenso), la sentencia se dictaba por el correspondiente Juzgado de Primera Instancia e Instrucción.
} 
al divorcio (en las dos, la demandante fue la mujer). Por su parte, en relación con la separación de personas y bienes, las dos sentencias dictadas por la Audiencia soriana fueron desestimatorias (las dos demandas fueron presentadas por la mujer). ${ }^{86}$

Cuadro 10. Sentencias dictadas por la Audiencia Provincial de Soria en causas de divorcio vincular y separación de personas y bienes $(1932-1936)^{87}$

\begin{tabular}{|c|c|c|c|c|c|c|}
\hline & & & Div & & Sepa & ación \\
\hline FECHA & NUM & $\begin{array}{l}\text { Juzgado instructor del } \\
\text { expediente }\end{array}$ & $\begin{array}{c}\text { Ha lugar al } \\
\text { divorcio }\end{array}$ & $\begin{array}{c}\text { No ha } \\
\text { lugar al } \\
\text { divorcio }\end{array}$ & $\begin{array}{c}\text { Estimando la } \\
\text { demanda }\end{array}$ & $\begin{array}{l}\text { Desestimando } \\
\text { la demanda }\end{array}$ \\
\hline & & & Año 1932 & & & \\
\hline 23.7 .1932 & $1 / 32$ & El Burgo de Osma & $\mathrm{M}$ & & & \\
\hline & & & Año 1933 & & & \\
\hline 28.4 .1933 & $1 / 33$ & El Burgo de Osma & & $\mathrm{M}$ & & \\
\hline 17.10 .1933 & $2 / 33$ & El Burgo de Osma & $\mathrm{M}$ & & & \\
\hline 23.11 .1933 & $3 / 33$ & Almazán & $\mathrm{M}$ & & & \\
\hline & & & Año 1934 & & & \\
\hline 27.1 .1934 & $1 / 34$ & Almazán & $\mathrm{M}$ & & & \\
\hline 9.2 .1934 & $2 / 34$ & Soria & $\mathrm{V}$ & & & \\
\hline 2.5 .1934 & $3 / 34$ & Agreda & V & & & \\
\hline 29.5 .1934 & $4 / 34$ & El Burgo de Osma & $\mathrm{V}$ & & & \\
\hline 30.5 .1934 & $5 / 34$ & El Burgo de Osma & $\mathrm{M}$ & & & \\
\hline 26.7 .1934 & $6 / 34$ & Soria & & & & $\mathrm{M}$ \\
\hline 20.10 .1934 & $7 / 34$ & Medinaceli & $\mathrm{V}$ & & & \\
\hline & & & Año 1935 & & & \\
\hline 7.6.1935 & $1 / 35$ & Soria & & & & $\mathrm{M}$ \\
\hline 2.11 .1935 & $2 / 35$ & El Burgo de Osma & $\mathrm{V}$ & & & \\
\hline & & & Año 1936 & & & \\
\hline 5.3 .1936 & $1 / 36$ & Almazán & & $\mathrm{M}$ & & \\
\hline 29.6.1936 & $2 / 36$ & El Burgo de Osma & $\mathrm{V}$ & & & \\
\hline 30.6 .1936 & $3 / 36$ & El Burgo de Osma & $\mathrm{M}$ & & & \\
\hline 8.7 .1936 & $4 / 36$ & Almazán & $\mathrm{V}$ & & & \\
\hline
\end{tabular}

NUM (número de sentencia). V -varón/esposo-, M -mujer/esposa-. (V o M, demandante en el proceso concreto).

Fuente: Archivo Histórico Provincial de Soria, signatura 7966. Audiencia Provincial de Soria. Libros de Sentencias. Libro núm. 59. Boletín Oficial de la Provincia de Soria de 23.9.1932. Elaboración propia.

86 Archivo Histórico Provincial de Soria, signatura 7966. Audiencia Provincial de Soria. Libros de Sentencias. Libro núm. 59. También en el Boletín Oficial de la Provincia de Soria de 23 de septiembre de 1932. Asimismo, se pueden obtener datos parciales sobre los divorcios en Soria en el Anuario Estadístico de España (años 1932 y 1933), año XIX, 1934, Madrid, Presidencia del Consejo de Ministros, Dirección General del Instituto Geográfico, Catastral y de Estadística, 1935, pp. 631 y 632 (aunque siempre será mejor contar con la fuente primaria que suponen las propias sentencias originales antes analizadas). En relación con el divorcio en la II República, CASTAÑO PENALVA, M., El divorcio en la Segunda República española: antecedentes y desarrollo, tesis doctoral, directora: María José Vilar García, Universidad de Murcia, Facultad de Letras, 2016 (en concreto, en relación con el impacto socio-político de la Ley del Divorcio de 1932 y su evolución -la cuestión hasta el inicio del conflicto bélico-, p. 415); también RODRÍGUEZ SERRADOR, S., "El divorcio en Valladolid durante la II República (1931-1937)”, en Investigaciones históricas, época moderna y contemporánea, núm. 39, 2019, pp. 577-620.

${ }^{87}$ Hasta el 18 de julio de 1936. En lo que resta de 1936 no se dictó sentencia alguna. Por otro lado, en 1937 se dictaron dos sentencias de separación de bienes y personas (de fechas 9 de julio y 23 de septiembre). 
También, conforme a la Ley de arrendamientos rústicos del 15 de marzo de 193588, la Audiencia Provincial de Soria sería la competente en materia civil para conocer de los recursos de apelación contra las resoluciones que dictaran los Juzgados de Primera Instancia e Instrucción de su provincia ${ }^{89}$. Sin embargo, lo cierto es que no se tienen datos de ningún procedimiento ni sentencia sobre esta materia arrendaticia en el tribunal soriano, ya sea porque no hubo ninguno o porque no se conservan libros de registro ni expedientes o legajos al respecto. ${ }^{90}$

III.3. Ámbito de actuación de partido judicial y municipio. Juzgados de Primera Instancia e Instrucción de Ágreda, Almazán, El Burgo de Osma, Medinaceli y Soria. Juzgados Municipales

\section{III.3.1. Personal}

Durante la II República ejercieron sus funciones judiciales como jueces titulares de los cinco Juzgados de Primera Instancia e Instrucción de la provincia de Soria (Ágreda, Almazán, El Burgo de Osma, Medinaceli y Soria) un total de 11 jueces. Al mismo tiempo, serían también 11 los secretarios judiciales de los mismos órganos judiciales.

Por lo que respecta a los jueces municipales de la provincia de Soria durante la II República, en las poblaciones de las cabeceras de los cinco partidos judiciales los mismos fueron un total de 11, siendo 9 los fiscales municipales (se detallan en el siguiente cuadro). Los jueces municipales de todos los pueblos de la provincia y que hacían un total de 348, tanto titulares como suplentes (salvo los de la cabecera de partido judicial), cuando ya no se elegían por votación entre los vecinos, se recogieron en los Boletines Oficiales de la Provincia de Soria de 20, 22 y 24 de agosto de 1934 (con el nombramiento efectuado por la Sala de Gobierno de la Audiencia Territorial de Burgos fechado el 13 de agosto de 1934, por la que se llevaba a cabo la renovación extraordinaria de los funcionarios de la justicia municipal). ${ }^{91}$

\footnotetext{
${ }^{88}$ Gaceta de Madrid núm. 83 de 24 de marzo de 1935.

${ }^{89}$ Así hasta la Ley de 28 de junio de 1940 (Boletín Oficial del Estado núm. 195 de 13 de julio de 1940), por la que se normaliza el régimen de arrendamientos rústicos, y se establece la competencia de las apelaciones en esta materia a favor de las Audiencias Territoriales (en el caso de la provincia de Soria, de la Audiencia Territorial de Burgos).

${ }^{90} \mathrm{Ni}$ en el Archivo Histórico Provincial de Soria, signatura 7966, Audiencia Provincial de Soria, libros de Sentencias, libro núm. 59, ni en ninguna otra signatura de las ya analizadas en anteriores epígrafes sobre la Audiencia soriana en el Archivo Histórico Provincia de Soria en todos los órdenes jurisdiccionales.

${ }^{91}$ En virtud de la ley de 27 de junio de 1934 (artículo único, apartado D). Hay que tener en cuenta (como ya se ha señalado en el capítulo II), que al inicio de la II República el nombramiento de los jueces municipales estaba regulado por la Ley Municipal de 5 de agosto de 1907, y el Decreto de 8 de mayo de 1931 introdujo la posibilidad de designación de los jueces municipales para poblaciones no cabezas de partido judicial, con menos de 12.000 habitantes, por libre elección de los vecinos mayores de veinticinco años que figuraran en las listas electorales vigentes en la fecha de la elección. Sin embargo, la Ley de 27 de junio de 1934 derogó dicha normativa sobre la designación de los jueces municipales por el pueblo, volviéndose a la situación anterior regulada por la Ley Municipal de 1907 (nombramiento de jueces municipales por las Audiencias Territoriales en pleno, con asistencia de los decanos de los colegios de abogados y notarios). Sobre la designación de los jueces municipales pueden verse también los artículos publicados en El Avisador Numantino de 29 de abril de 1931 y en La Voz de Soria de 9 de octubre de 1934. Por otro lado, el Decreto de 31 de enero de 1934 (Gaceta de Madrid núm. 33 de 2 de febrero de 1934, pp. 874 y 875), estableció que los secretarios de Juzgados Municipales formarían a partir de entonces un cuerpo auxiliar de la Administración de Justicia denominado Cuerpo de Secretarios de Juzgado Municipal.
} 
Cuadro 11. Jueces y secretarios de los cinco Juzgados de Primera Instancia e Instrucción de la provincia de Soria (1931-1936) (entre paréntesis su concreto período de actividad)

\begin{tabular}{|c|c|c|}
\hline Juzgado & Jueces & Secretarios \\
\hline Ágreda & $\begin{array}{l}\text { José Fuentes Fuentes (1929-1932), } \\
\text { Francisco Corrales Asenjo-Barbieri (1932- } \\
\text { 1933) y José María Cabrera Claver (1933- } \\
\text { 1936) }\end{array}$ & Juan Azcune Echevarría (1926-1941) \\
\hline Almazán & $\begin{array}{l}\text { Jacinto García Monge Martín (1927-1936) } \\
\text { y Luis Jiménez Estárez Armijo (1936- } \\
\text { 1939) }\end{array}$ & $\begin{array}{l}\text { Juan José Luis Guillén (1929-1933), } \\
\text { Vicente Rocher Jordá (1933-1934) y José } \\
\text { Gómez Díaz (1934-1943) }\end{array}$ \\
\hline $\begin{array}{l}\text { El Burgo de } \\
\text { Osma }\end{array}$ & Francisco Palanco Romero (1929-1940) & Luis Salazar Martínez (1933-1934) ${ }^{92}$ \\
\hline Medinaceli & $\begin{array}{l}\text { Alfonso Bernáldez Ávila (1926-1933) y } \\
\text { Eduardo Junco Mendoza (1933-1945) }\end{array}$ & $\begin{array}{l}\text { Francisco Jerez García (1934) y Luis } \\
\text { Pensado Cardama (1935-1938) }\end{array}$ \\
\hline Soria & $\begin{array}{l}\text { Nicolás Salvador Solera Martínez (1930- } \\
\text { 1931), Jesús Urrutia Castillo (1931-1933) y } \\
\text { Teófilo Francisco Pérez Amaro (1933- } \\
\text { 1944) }\end{array}$ & $\begin{array}{l}\text { José Gómez de la Torre y Villa (1931- } \\
\text { 1933), Aniceto Bocos de Francisco } \\
\text { (1933-1934), José Roda Rodríguez (1934) } \\
\text { y Emiliano Corral Fernández (1934- } \\
\text { 1938) }\end{array}$ \\
\hline
\end{tabular}

Fuente: Archivo Histórico Provincial de Soria (Juzgados de Ágreda y Soria); Archivo del Juggado de Primera Instancia e Instrucción de Almazán (Juzgados de Almazán y Medinaceli); Archivo del Juzgado de Primera Instancia e Instrucción de El Burgo de Osma. También Gaceta de Madrid y Boletín Oficial de la Provincia de Soria (nombramientos y ceses). Elaboración propia.

Cuadro 12. Jueces y fiscales de los Juzgados Municipales (1931-1936). Sólo las poblaciones que eran cabecera de los cinco partidos judiciales de la provincia de Soria (entre paréntesis su concreto período de actividad).

\begin{tabular}{|c|l|l|}
\hline Juzgado & \multicolumn{1}{|c|}{ Jueces Municipales } & \multicolumn{1}{c|}{ Fiscales Municipales } \\
\hline Ágreda & $\begin{array}{l}\text { Marcos Bueno Gordo (1931-1934) y Francisco } \\
\text { Pérez Caballero de Córdoba (1934-) }\end{array}$ & $\begin{array}{l}\text { Celestino García Cazcarro (1931-1934) y } \\
\text { Aquilino Vizmanos López (1934-) }\end{array}$ \\
\hline \multirow{2}{*}{ Almazán } & $\begin{array}{l}\text { Ángel Arpón de Mendivi (1931-1934), Carlos } \\
\text { Alonso Torrubia (1934-1935) y Andres Moliner } \\
\text { González (1936-) }\end{array}$ & $\begin{array}{l}\text { Juan Manuel Pedroviejo Ibáñez (1931- } \\
\text { 1934) y Aurelio Ramírez Arranz (1934-) }\end{array}$ \\
\hline El Burgo de Osma & $\begin{array}{l}\text { Santiago del Val Llorente (1931-1934) y Fermín } \\
\text { Lucas de la Rica (1934-) }\end{array}$ & $\begin{array}{l}\text { Victoriano Almería Ibarra (1931-1934) y } \\
\text { Deogracias Ruiz Miguel (1934-) }\end{array}$ \\
\hline Medinaceli & Pedro Gil Saldaña (1931-1936)95 & Bernabé Ramos Bonillo (1931-1934 y 1935-) \\
\hline \multirow{2}{*}{ Soria } & $\begin{array}{l}\text { Bernabé Herrero Zardoya (1931-1932), } \\
\text { Valentín Ropero Calonge (1932-1935) y Casto } \\
\text { Granados Aguirre (1936-) }\end{array}$ & $\begin{array}{l}\text { Matías Gracias López (1931-1934) y Víctor } \\
\text { Higes Cuevas (1935-) }\end{array}$ \\
\hline
\end{tabular}

Fuente: Archivo Histórico Provincial de Soria (Juzgados de Ágreda y Soria); Archivo del Jurgado de Primera Instancia e Instrucción de Almazán (Juzgados de Almazán y Medinaceli); Archivo del Juzgado de Primera Instancia e Instrucción de El Burgo de Osma; Boletín Oficial de la Provincia de Soria, entre otros, 8.6.1931, 12.6.1931, 5.9.1932, 16.11.1934, 22.11.1935 y 24.6.1936 (con nombramiento efectuado por la Audiencia Territorial de Burgos). Elaboración propia.

\footnotetext{
92 Antes y después estuvo vacante la Secretaría del Juzgado de El Burgo de Osma (anteriormente, hasta 1929 la ocupó Mariano Pérez Peinado). Durante el período vacante consta la firma como secretario (De Su Orden) de Juan Romero.

${ }^{93}$ En 1934 y 1935 actuó como juez de Instrucción de Medinaceli en varias ocasiones el juez municipal Pedro Gil Saldaña.

${ }^{94}$ Hasta 1934 estuvo vacante la Secretaría del Juzgado de Medinaceli en diferentes períodos, desempeñando el cargo en alguna ocasión con anterioridad Manuel Muñoz Guerra. Entre 1934 y 1935 fue secretario habilitado algunas veces Víctor García.

${ }^{95}$ En funciones de juez de Primera Instancia e Instrucción de Medinaceli en muchas ocasiones.

${ }^{96}$ Nicolás Bujarrabal de las Mercedes, que era juez municipal suplente de Soria desde 1931, sustituyó al titular bastantes veces entre 1935 y 1936.
} 


\section{III.3.2. Actividad judicial}

En el ámbito del partido judicial, en relación con la jurisdicción penal, el número de asuntos (sumarios) incoados por los cinco Juzgados de Primera Instancia e Instrucción de la provincia de Soria (Ágreda, Almazán, El Burgo de Osma, Medinaceli y Soria) durante la II República, ascendió a un total de 2.134 asuntos. De ellos, el Juzgado de Primera Instancia e Instrucción de Soria fue el que más causas incoó, con 781, lo que supuso un 37\% del total provincial. Le seguiría el Juzgado de Primera Instancia e Instrucción de El Burgo de Osma con 463 (un 22\% del total). Por lo que respecta al año en el que más causas penales se incoaron fue 1934, con un total de 447.

Cuadro 13. Número de asuntos penales (sumarios) incoados en cada uno de los cinco Juzgados de Primera Instancia e Instrucción de la provincia de Soria (1931-1936) ${ }^{97}$

\begin{tabular}{|c|c|c|c|c|c|c|c|c|}
\hline $\begin{array}{c}\text { Juzgado de Primera } \\
\text { Instancia e Instrucción / Año }\end{array}$ & 1931 & 1932 & 1933 & 1934 & 1935 & 1936 & Totales & $\%$ \\
\hline Agreda & 38 & 47 & 53 & 48 & 40 & 20 & 246 & 11 \\
\hline Almazán & 58 & 87 & 60 & 100 & 76 & 35 & 416 & 20 \\
\hline El Burgo de Osma & 62 & 91 & 79 & 101 & 76 & 54 & 463 & 22 \\
\hline Medinaceli & 20 & 42 & 35 & 52 & 53 & 26 & 228 & 10 \\
\hline Soria & 119 & 150 & 118 & 146 & 153 & 95 & 781 & 37 \\
\hline Totales & 297 & 417 & 345 & 447 & 398 & 230 & 2134 & 100 \\
\hline
\end{tabular}

Fuente: Arcbivo Histórico Provincial de Soria, Signaturas 5332, 8413 y 8820 (Juzgados de Ágreda y Soria); Arcbivo del Juzgado de Primera Instancia e Instrucción de Almazán, cajas 1 y 5 archivo 1, cajas 1 y 2 y libro 1935-1936 archivo 2 (Juzgados de Almazán y Medinaceli); Archivo del Juzgado de Primera Instancia e Instrucción de El Burgo de Osma, cajas 14 y 35; Anuario Estadístico de España. Justicia. Instituto Nacional de Estadística (1931-1936). Elaboración propia.

Si nos referimos a la jurisdicción civil, el número total de asuntos civiles incoados en los cinco Juzgados de Primera Instancia e Instrucción de la provincia de Soria durante la II República, fue de 1.037, de los que 486 lo serían en el Juzgado de Primera Instancia e Instrucción de Soria (47\% del total provincial), seguido por los 181 asuntos incoados en el Juzgado de Primera Instancia e Instrucción de Ágreda (17\% del total). El año en el que más asuntos civiles se registraron de todo el período sería 1933 con un total de 220 asuntos.

Cuadro 14. Número de asuntos civiles incoados en cada uno de los cinco Juzgados de Primera Instancia e Instrucción de la provincia de Soria (1931-1936) ${ }^{98}$

\begin{tabular}{|c|c|c|c|c|c|c|c|c|}
\hline $\begin{array}{c}\text { Juzgado de Primera } \\
\text { Instancia e Instrucción / Año }\end{array}$ & 1931 & 1932 & 1933 & 1934 & 1935 & 1936 & Totales & $\%$ \\
\hline Agreda & 30 & 34 & 30 & 23 & 48 & 16 & 181 & 17 \\
\hline Almazán & 14 & 32 & 28 & 14 & 33 & 26 & 147 & 14 \\
\hline El Burgo de Osma & 20 & 35 & 31 & 28 & 25 & 18 & 157 & 15 \\
\hline Medinaceli & 17 & 8 & 11 & 9 & 10 & 11 & 66 & 7 \\
\hline Soria & 67 & 93 & 120 & 89 & 69 & 48 & 486 & 47 \\
\hline Totales & 148 & 202 & 220 & 163 & 185 & 119 & 1037 & 100 \\
\hline
\end{tabular}

Fuente: Archivo Histórico Provincial de Soria, Signaturas 5329 y 8421 (Juzgados de Ágreda y Soria); Archivo del Juzgado de Primera Instancia e Instrucción de Almazán, caja 1 archivo 1; Archivo Histórico Provincial de Soria, signaturas 55583 a 55586 (Juzgado de Medinaceli); Archivo del Juagado de Primera Instancia e Instrucción de El Burgo de Osma, caja 21. Elaboración propia.

${ }^{97}$ Desde el 14 de abril de 1931 hasta el 18 de julio de 1936.

${ }^{98}$ Desde el 14 de abril de 1931 hasta el 18 de julio de 1936. 
En relación con los divorcios y separaciones de personas y bienes incoados por los cinco Juzgados de Primera Instancia e Instrucción de la provincia entre 1932 y 1936, los mismos fueron un total de 19 divorcios y 6 separaciones. ${ }^{99}$

En el ámbito del municipio, es de todo punto imposible determinar el número de procedimientos totales y parciales de los que conocieron los 348 jueces municipales de la provincia de Soria durante la II República, fundamentalmente juicios verbales (en civil) y juicios de faltas (en penal ${ }^{100}$. Por ello, una forma indirecta de aproximarnos a la labor que llevaron a cabo los distintos Juzgados Municipales en la provincia de Soria en el período republicano, será el estudio de los recursos de apelación, tanto penales como civiles, que fueron incoados por los Juzgados de Primera Instancia e Instrucción de la cabecera de cada partido judicial con respecto a las sentencias dictadas por los propios jueces municipales de su respectivo ámbito de partido (de todos menos del Juzgado de Primera Instancia e Instrucción de El Burgo de Osma, ya que en el mismo no se conservan libros de registro de asuntos de apelación, ni expedientes o legajos en relación con dichos recursos).

Así, en relación con las apelaciones penales incoadas en los Juzgados de Primera Instancia e Instrucción de la provincia de Soria, en virtud de recurso interpuesto contra las sentencias dictadas en juicios de faltas por los distintos Juzgados Municipales, las mismas fueron un total de 386 en toda la provincia, siendo el Juzgado de Primera Instancia e Instrucción de Soria el que más recursos de apelación registró, con un total de 149, seguido del Juzgado de Primera Instancia e Instrucción de Ágreda en el que se incoaron 112.

Dentro de la jurisdicción civil, el número de apelaciones incoadas en los Juzgados de Primera Instancia e Instrucción de la provincia de Soria, en virtud de recurso interpuesto contra las sentencias dictadas en los juicios verbales por los diferentes Juzgados Municipales fueron un total de 547, de las que el Juzgado de Primera Instancia e Instrucción de Soria incoó un total de 284, seguido por el de Almazán con 108.

\footnotetext{
99 Ágreda: 1 divorcio (primera, y única, demanda de 6 de noviembre de 1932); Almazán: 5 divorcios y 1 separación (primera demanda de 14 de mayo de 1932); El Burgo de Osma: 7 divorcios (primera demanda de 21 de abril de 1932); Medinaceli: 1 divorcio y 3 separaciones (primera demanda de 15 de mayo de 1934); y Soria: 5 divorcios y 2 separaciones. La primera demanda de divorcio se presentó en el Juzgado de Primera Instancia e Instrucción de Soria el 19 de abril de 1932. En el caso de que el divorcio o la separación lo solicitaran ambos cónyuges de mutuo acuerdo (mutuo disenso), la sentencia se dictaba por el correspondiente Juzgado de Primera Instancia e Instrucción. Archivo Histórico Provincial de Soria, Signaturas 5329 y 8421 (Juzgados de Ágreda y Soria); Archivo del Juzgado de Primera Instancia e Instrucción de Almazán, caja 1 archivo 1; Archivo Histórico Provincial de Soria, signaturas 55583 a 55586 (Juzgado de Medinaceli); Archivo del Juzgado de Primera Instancia e Instrucción de El Burgo de Osma, caja 21.

100 Por un lado, por la ingente labor numérica que conllevaría su recopilación (348 juzgados municipales de otros tantos municipios de la provincia), pero, por otro, y más importante, porque aunque se intentara, no se podría llevar a cabo porque no se conservan la inmensa mayoría de los libros, expedientes y legajos al respecto en todos y cada uno de dichos municipios (aun cuando un puñado pequeño de ellos sí que se conservan en el archivo de cada Juzgado de la cabecera de su partido judicial y en el Archivo Histórico Provincial de Soria).
} 
Cuadro 15. Número de apelaciones penales incoadas durante la II República en cuatro de los cinco Juzgados de Primera Instancia e Instrucción de la provincia de Soria ${ }^{101}$ en virtud de recurso contra las sentencias dictadas en juicios de faltas por los Juzgados Municipales de su respectivo partido judicial.

\begin{tabular}{|c|c|c|c|c|c|c|c|}
\hline $\begin{array}{c}\text { Juzgado de Primera } \\
\text { Instancia e Instrucción / Año }\end{array}$ & 1931 & 1932 & 1933 & 1934 & 1935 & 1936 & Totales \\
\hline Agreda & 16 & 21 & 17 & 15 & 36 & 7 & 112 \\
\hline Almazán & 15 & 9 & 10 & 8 & 13 & 9 & 64 \\
\hline Medinaceli & 7 & 8 & 23 & 5 & 14 & 4 & 61 \\
\hline Soria & 21 & 20 & 28 & 36 & 36 & 8 & 149 \\
\hline Totales & 59 & 58 & 78 & 64 & 99 & 28 & 386 \\
\hline
\end{tabular}

Fuente: Archivo Histórico Provincial de Soria, Signaturas 5329, 8824 y 19209 (Juzgados de Ágreda y Soria); Archivo del Juzgado de Primera Instancia e Instrucción de Almazán, caja 1 archivo 2 y caja 6 archivo 1 (Juzgados de Almazán y Medinaceli). Elaboración propia.

Cuadro 16. Número de apelaciones civiles incoadas durante la II República en cuatro de los cinco Juzgados de Primera Instancia e Instrucción de la provincia de Soria ${ }^{102}$ en virtud de recurso contra las sentencias dictadas en juicios verbales por los Juzgados Municipales de su respectivo partido judicial.

\begin{tabular}{|c|c|c|c|c|c|c|c|}
\hline $\begin{array}{c}\text { Juzgado de Primera } \\
\text { Instancia e Instrucción / Año }\end{array}$ & 1931 & 1932 & 1933 & 1934 & 1935 & 1936 & Totales \\
\hline Agreda & 18 & 20 & 17 & 21 & 22 & 7 & 105 \\
\hline Almazán & 11 & 42 & 29 & 8 & 14 & 4 & 108 \\
\hline Medinaceli & 5 & 11 & 11 & 11 & 9 & 3 & 50 \\
\hline Soria & 47 & 66 & 38 & 60 & 46 & 27 & 284 \\
\hline Totales & 81 & 139 & 95 & 100 & 91 & 41 & 547 \\
\hline
\end{tabular}

Fuente: Archivo Histórico Provincial de Soria, Signaturas 5329, 8421, 8824 y 19209 (Juzgados de Ágreda y Soria); Archivo del Juzgado de Primera Instancia e Instrucción de Almazán, cajas 1 y 2 archivo 1 (Juzgados de Almazán y Medinaceli). Elaboración propia.

\section{Conclusiones}

A lo largo de la II República se produjo una sacudida en España desde el punto de vista jurídico como difícilmente se había conocido con anterioridad en nuestro ordenamiento. Sobre todo en tan poco tiempo. Durante el régimen republicano entre 1931 y 1936 se llevaron a cabo muchas reformas normativas. En este trabajo, sumando leyes y decretos, se han documentado 56 nuevas disposiciones que, de una u otra manera, afectaron directamente a la propia Administración de Justicia.

No se ha dedicado demasiado tiempo de estudio y análisis a la Justicia durante el período republicano desde un punto de vista histórico-jurídico, sobre todo si lo comparamos con la mayor atención que se ha prestado a la misma en los dos períodos siguientes (guerra civil y posguerra). Si esa afirmación pudiera ser válida a nivel general para toda España, mucho más lo será de forma particular con respecto a Soria.

${ }^{101}$ Con respecto al Juzgado de Primera Instancia e Instrucción de El Burgo de Osma, no se conservan los libros de registro ni expedientes ni legajos en relación con las apelaciones penales incoadas en virtud de recurso contra las sentencias dictadas por los Juzgados Municipales de su partido judicial en los juicios de faltas entre $1931 \mathrm{y}$ 1936. Archivo del Juzgado de Primera Instancia e Instrucción de El Burgo de Osma.

${ }^{102}$ Con respecto al Juzgado de Primera Instancia e Instrucción de El Burgo de Osma, no se conservan los libros de registro ni expedientes en relación con las apelaciones civiles incoadas en virtud de recurso contra las sentencias dictadas por los Juzgados Municipales de su partido judicial en los juicios verbales entre 1931 y 1936. Archivo del Juzgado de Primera Instancia e Instrucción de El Burgo de Osma. 
La II República vino de forma pacífica. Por ello, el ordenamiento jurídico existente con anterioridad fue recogido sin ningún trauma. También en Soria. Además, la estabilidad fue razonable en los miembros de la Justicia soriana durante todo el devenir histórico republicano, comenzando ya desde los primeros momentos tras la proclamación del nuevo régimen. A partir del 14 de abril de 1931 se produjeron en Soria únicamente algunos cambios en la Judicatura fundamentalmente motivados por traslados ordinarios o por alguna que otra jubilación forzosa por edad. ${ }^{103}$

La Administración de Justicia en Soria se fue adaptando estructuralmente sin ningún problema de una manera sistemática y secuencial a las distintas reformas sustantivas y procesales que se fueron aprobando durante la II República. En su virtud, por un lado, la Audiencia Provincial de Soria asumió internamente la nueva estructura que conllevaba el restablecimiento del Tribunal del Jurado, así como la constitución cada cierto tiempo del Tribunal de Urgencia que preveía la Ley de Orden Público a partir de 1933, o también la relativa a la sustanciación de determinados procedimientos en relación con la Ley de Vagos y Maleantes. Por otro, asumió nuevas competencias, siendo una de las más importantes la relativa en materia civil al divorcio. No consta en la documentación estudiada, tanto judicial como gubernativa, ningún hecho negativo digno de mención, ya sea puntual o continuado en el tiempo, en relación con la actividad judicial y administrativa diaria de los distintos órganos judiciales sorianos.

Independientemente de que hubiera más o menos conflictividad social y política en Soria y provincia a lo largo de la II República (cosa que, en comparación con otros territorios, fue bastante escasa), lo cierto es que, del exhaustivo estudio llevado a cabo de toda la documentación judicial oficial que se conserva, se extrae la conclusión de que en Soria existieron pocos episodios significativos de importancia de los que luego tuviera que conocer la Administración de Justicia y cuyo detonante directo o indirecto fuera el propio régimen (a salvo siempre la comisión de determinados delitos comunes, más o menos violentos, que diferían poco en tipología y asiduidad en comparación con otros períodos históricos judiciales). En su virtud, excepto algunas peculiaridades propias y particulares de adaptación motivadas por las singulares reformas normativas ya analizadas, se puede concluir que la normalidad en la actividad judicial de la Administración de Justicia en Soria fue la tónica general durante la II República.

${ }^{103}$ En la documentación judicial analizada no se ha constatado ningún traslado con carácter forzoso o que alguna jubilación por edad lo hubiera sido nominalmente por "depuración” gubernamental (el hecho de que durante la II República, en algo más de 5 años, hubiera 6 presidentes de la Audiencia Provincial de Soria, se debe a relevos motivados por cambios organizativos y no a "depuraciones" políticas, como lo demuestra la circunstancia de que algunos de ellos fueran magistrados del propio tribunal soriano tras su período como presidentes, y otros a la inversa). En cuanto a la finalización del período republicano, a partir del 18 de julio de 1936, la estabilidad también fue habitual en la Judicatura soriana y, por extensión, en el personal propio de su Administración de Justicia (salvo ciertas excepciones: así, aunque el mismo no formara parte en puridad de la Judicatura, Ricardo Gullón Fernández, teniente fiscal de la Audiencia Provincial de Soria en 1936, fue expedientado en 1940 y posteriormente sancionado con traslado forzoso en 1941; también se produjo el cese de algún magistrado suplente del tribunal tras el 18 de julio de 1936, y bastantes jueces municipales; en algún que otro caso, tras el acuerdo puntual de cese vendría una pronta readmisión a su anterior destino). Por otro lado, el ejemplo más paradigmático de estabilidad en el tiempo, al prolongarse posteriormente mucho más allá de los propios parámetros del régimen republicano, lo encontramos en Jesús Urrutia Castillo, que vino a Soria como juez de Primera Instancia e Instrucción de la capital (y lo fue entre 1931 y 1933), con posterioridad sería magistrado de la Audiencia Provincial de Soria entre 1933 y 1939 y, finalmente, fue presidente del propio tribunal soriano desde 1939, ni más ni menos, que hasta 1957. 


\section{Fuentes y bibliografía}

Fuentes

Archivos

- Archivo Histórico Provincial de Soria

Audiencia Provincial de Soria

Juzgados de Primera Instancia e Instrucción de Ágreda, Medinaceli y Soria

- Archivo del Juzgado de Primera Instancia e Instrucción de Almazán

Juzgados de Primera Instancia e Instrucción de Almazán y Medinaceli

- Archivo del Juzgado de Primera Instancia e Instrucción de El Burgo de Osma

\section{Boletines oficiales}

- Gaceta de Madrid

- Boletín Oficial de la Junta de Defensa Nacional de España

- Boletín Oficial del Estado

- Boletín Oficial de la Provincia de Soria

Periódicos de la época

- El Avisador Numantino

- El Noticiero de Soria

- La Voz de Soria

- Hogar y Pueblo

Otras

- Anuario Estadístico de España, año XIX, 1934, Madrid, Presidencia del Consejo de Ministros, Dirección General del Instituto Geográfico, Catastral y de Estadística, 1935.

- Memoria elevada al Gobierno de la República con motivo de la solemne apertura de los Tribunales el día 15 de septiembre de 1933 por el Fiscal General de la República, Madrid, Editorial Reus, 1933

Bibliografía citada

AQUESOLO VEGAS, José, “Apuntes sobre la Justicia en España 1931-1945. La documentación que se conserva en un archivo histórico provincial", en Los años convulsos. 1931-1945. Documentación del Archivo Histórico Provincial de Málaga, VVAA, Esther Cruces Blanco y José Aquesolo Vegas (coordinadores), Cádiz, Junta de Andalucía, Consejería de Cultura, 2006, pp. 53-65. 
CALVO VILLAR, Carmen, "La Instrucción Pública en Soria capital durante la Segunda República Española (1931-1936)", en Celtiberia, núm. 85-86, Soria, Centro de Estudios Sorianos, 1993, pp. 159-201.

CASTAÑO PENALVA, Máximo, El divorcio en la Segunda República española: antecedentes y desarrollo, tesis doctoral, directora: María José Vilar García, Universidad de Murcia, Facultad de Letras, 2016.

CID SABUCEDO, Alfonso, y SOTO FERNÁNDEZ, José Roberto, “Evolución de protección de menores en la provincia de Ourense (1936-1960)", en Minius, núm. 15, Universidad de Vigo, 2007, pp. 49-65.

CRESPO MONTES, Luis Fernando, y FERNÁNDEZ FERNÁNDEZ, María Elia., “Apuntes para un estudio de la demarcación judicial española”, en Boletín del Ministerio de Justicia, núm. 1624, 1992, pp. 119-165.

DÍAZ-PLAJA CONTESTÍ, Fernando, La Segunda República. Primeros pasos, Barcelona, Planeta, 1995.

FRÍAS RUBIO, Ana Rosa, "El Tribunal de Responsabilidades Políticas de Soria. 1939-1959”, en RICUS (Geografía e Historia), Tomo XI, núm. 3, Colegio Universitario de Soria, 1990-1991, pp. $87-113$.

GARCÍA LEÓN, Susana, "El control judicial durante la II República Española. La actuación de la Audiencia Territorial de Madrid como mecanismo de inspección de los tribunales", en Control y responsabilidad de los jueces (siglos XVI-XXI), VVAA, José Sánchez-Arcilla Bernal (investigador principal), Madrid, Dykinson, 2017, pp. 427-470.

GARCÍA SEGURA, María Concepción, Historia de la Diputación Provincial de Soria, Siglo XX (años 19022005), Soria, Diputación Provincial de Soria, 2005, capítulo X (La Diputación de Soria durante la Segunda República y la Guerra Civil), pp. 185-306.

GENERELO LANASPA, Juan José, "La primera jurisdicción laboral: los Tribunales Industriales y su documentación (1908-1938)", en La Administración de Justicia en la Historia de España, Actas de las III Jornadas de Castilla-La Mancha sobre investigación en archivos, VVAA, Guadalajara, Junta de Castilla-La Mancha, 1999, pp. 1075-1120.

GÓMEZ LOECHES, Luis., "El expurgo en los archivos judiciales”, en La Administración de Justicia en la historia de España, Actas de las III Jornadas de Castilla-La Mancha sobre investigación en archivos, Vol. II, Guadalajara, Junta de Castilla-La Mancha, 1999, pp. 829-849.

GÓMEZ TIERNO, Jesús, La Audiencia de lo Criminal de Soria, tesis doctoral, directora: Isabel Martínez Navas, Facultad de Ciencias Jurídicas y Sociales, Departamento de Derecho, Universidad de La Rioja, 2019.

GONZÁLEZ CALLEJA, Eduardo, "La necro-lógica de la violencia sociopolítica en la primavera de 1936”, en Mélanges de la Casa de Velázquez, núm. 41-1, 2011, pp. 37-60.

GONZÁLEZ CALLEJA, Eduardo, Cifras cruentas. Las victimas mortales de la violencia sociopolítica en la Segunda República Española (1931-1936), Albolote (Granada), Comares, 2015.

GONZÁlEZ CALLEJA, Eduardo, COBO ROMERO, Francisco, MARTíNEZ RUS, Ana, y SÁNCHEZ PÉREZ, Francisco, La Segunda República Española, Barcelona, Ediciones de Pasado y Presente, 2015.

GONZÁLEZ PÉREZ, Jesús, “Evolución de la legislación contencioso-administrativa”, en Revista de Administración Pública, núm. 150, septiembre-diciembre 1999, pp. 209-237. 
HERNÁNDEZ GARCÍA, Antonio, 640 sorianos represaliados por Franco, 2012.

HERRERO BALSA, Gregorio, y HERNÁNDEZ GARCÍA, Antonio, La represión en Soria durante la Guerra Civil, Soria, 1982.

MARÉS ROGER, Francisco, "El Tribunal del Jurado en la II República española”, en Boletín de Información del Ministerio de Justicia, año XLIX, núm. 1760, noviembre 1995, pp. 95-113.

MARTÍNEZ DHIER, Alejandro, “Apuntes sobre la vagancia y su represión durante la II República española: la Ley de Vagos y Maleantes de 1933”, en Represión y Orden Público durante la II República, la Guerra Civily el Franquismo. Una visión comparada, VVAA, José Antonio Pérez Juan y Sara Moreno Tejada (coordinadores), Cizur Menor (Navarra), Thomson Reuters. Aranzadi, 2019, pp. 59-87.

MARZAL RODRÍGUEZ, Pascual, "Intervención política y judicatura española durante la II República”, en Glossae, European Journal of Legal History, núm. 12, 2015, pp. 549-562.

MONTÓN REDONDO, Alberto, Juggados y tribunales españoles. Origenes y atribuciones, Madrid, Tecnos, 1986.

MORENO MORENO, Miguel, Biografía curiosa de Soria, Soria, 1975.

MUÑOZ MACHADO, Santiago, "De la II República al siglo XXI, las transformaciones del Derecho en setenta años", en Revista Española de Derecho Constitucional, año 22, núm. 66, septiembrediciembre 2002, pp. 91-121.

PAYÁ POVEDA, José Miguel, Justicia, orden público y Tribunales de Urgencia en la II República, Cizur Menor (Navarra), Thomson Reuters, Aranzadi, 2017.

PAYÁ POVEDA, José Miguel, "El control gubernamental de la Justicia en el segundo bienio republicano. La inamovilidad de los jueces. La Ley Casanueva de 1935 y el traslado forzoso de magistrados y fiscales por el gobierno", en Represión y Orden Público durante la II República, la Guerra Civil y el Franquismo. Una visión comparada, VVAA, José Antonio Pérez Juan y Sara Moreno Tejada (coordinadores), Cizur Menor (Navarra), Thomson Reuters. Aranzadi, 2019, pp. 163-185.

RAMÍREZ JIMÉNEZ, Manuel, La legislación de la Segunda República Española (1931-1936), Madrid, Boletín Oficial del Estado, Centro de Estudios Políticos y Constitucionales, 2005.

REVUELTA GUERRERO, R. Clara, y GALENDE MATEOS, Águeda, "La prehistoria del Tribunal para Niños de Valladolid (1904-1948)", en El largo camino hacia una educación inclusiva: la educación especial y social del siglo XIX a nuestros días: XV Coloquio de Historia de la Educación, vol. 2, María Reyes Berruezo Albéniz y Susana Conejero López (coordinadoras), Pamplona, Universidad Pública de Navarra, 2009, pp. 311-324.

RODRÍGUEZ SERRADOR, Sofía, “El divorcio en Valladolid durante la II República (1931-1937)”, en Investigaciones históricas, época moderna y contemporánea, núm. 39, 2019, pp. 577-620.

ROLDÁN CAÑIZARES, Enrique, "La justicia de la II República Española en guerra. Una aproximación historiográfica”, en Revista de Historiografía, núm. 29, 2018, pp. 37-54.

ROMERO SALVADOR, Carmelo, Soria 1860-1936, Aspectos demográficos, socioeconómicos, culturales y politicos, Tomo II, Soria, Publicaciones de la Diputación Provincial de Soria, Colección Temas Sorianos, 1981, pp. 9-32. 
ROMERO SALVADOR, Carmelo, "Cronología. Historia Contemporánea", en Historia de Soria, Tomo II, VVAA, director: José Antonio Pérez-Rioja, Soria, Centro de Estudios Sorianos, 1985.

ROMERO SALVADOR, Carmelo, “Soria, Edad Contemporánea. Siglos XIX-XX (1808-1984)”, en Historia de Soria, Tomo I, VVAA, director: José Antonio Pérez-Rioja, Soria, Centro de Estudios Sorianos, 1985.

RUIZ, Julius, El Terror Rojo, traducción de Jesús de la Torre, Barcelona, Espasa, 2012.

SERRALLONGA URQUIDI, Joan, "El aparato provincial durante la Segunda República. Los gobernadores civiles, 1931-1939”, en Hispania Nova. Revista de Historia Contemporánea, Separata, núm. 7, 2007, pp. 1-52.

SINOVA GARRIDO, Justino, La Prensa en la Segunda República Española. Historia de una libertad frustrada, Barcelona, Debate, 2006.

VÁZQUEZ OSUNA, Federico, "La recuperación de la memoria histórica, la judicatura republicana", en XIX Congreso Estatal de Jueces para la Democracia, Barcelona, 13-15 de mayo de 2004, ponencia, pp. 1-34 (www.juecesdemocracia.es). Visita: 12.3.2020. 